\title{
Vibrational Analysis of Peptides, Polypeptides, and Proteins. I. Polyglycine I
}

\author{
W. H. MOORE and S. KRIMM, Harrison M. Randall Laboratory of \\ Physics and Biophysics Research Division, Institute of Science and \\ Technology, University of Michigan, Ann Arbor, Michigan 48109
}

\begin{abstract}
Synopsis
A force field has been refined for the antiparallel chain-rippled sheet structure of polyglycine I. Transition dipole coupling and hydrogen bonding are explicitly taken into account. Amide I and amide II mode splittings are well accounted for, the latter also providing a quantitative explanation of the amide $A$ and amide $B$ mode frequencies and intensities. In addition to predicting other features of the vibrational spectrum of polyglycine $I$, this force field is completely transferable to other $\beta$ polypeptides, even though these have the antiparallel chainpleated sheet structure.
\end{abstract}

\section{INTRODUCTION}

Vibrational spectroscopy provides a potentially powerful technique for studying the conformational structure of biological macromolecules. The realization of this potential, however, depends not only on obtaining ir and Raman spectra of such systems, but on the ability to interpret these spectra in the greatest possible detail. This kind of analysis can succeed only if a secure predictive capability exists; in other words, we require that experimental observation be complemented by theoretical normal vibration calculations. In this way it becomes possible to correlate spectral characteristics directly with conformational properties, and to do so with confidence in the conclusions.

The present series of papers has two primary goals: 1) to provide detailed vibrational analyses of the spectra of a class of important biological molecules, and 2) in doing so, to develop a force field that can be used to answer conformational questions concerning such systems. Our aim is to refine a force field with maximum transferability so that it can be applied successfully to the analysis of unknown structures.

In pursuing the above goals, we have adopted the procedure of building on the analysis of simpler molecules and working up to the more complex. Thus, we have refined a general valence force field for $N$-methyl acetamide and nylons and some of their deuterated derivatives, ${ }^{1}$ and have extended this to the spectra of some amides. ${ }^{2}$ This was then used to refine a force field for polyglycine $\mathrm{I}^{3}$ (Gly I) ${ }_{n}$ and polyglycine $\mathrm{II}^{4}(\mathrm{Gly} \mathrm{II})_{n}$, and to provide a further extension to polypeptides with beta carbon atoms. ${ }^{5}$ The latter 
analyses led to the recognition ${ }^{6,7}$ that transition dipole coupling terms were necessary to explain details of the amide I mode splittings in $\beta$ polypeptides, and therefore such terms had to be incorporated in peptide force fields.

Our attempt to extend the polypeptide force field to $\beta$ polypeptides other than (Gly I) ${ }_{n}$ encountered difficulties so long as we used the generally accepted antiparallel chain-pleated sheet (APPS) structure proposed by Pauling and Corey. ${ }^{8,9}$ In a reçent electron diffraction study Lotz ${ }^{10}$ has proposed that (Gly I) $n$ has an antiparallel chain-rippled sheet (APRS) structure, a conformation also suggested for $\beta$ polypeptides by Pauling and Corey. ${ }^{9}$ When we used this structure we found ${ }^{11}$ that the vibrational spectrum of (Gly I) ${ }_{n}$ could be explained more satisfactorily, and also that a transferable force field could now account well for the vibrational spectra of other $\beta$ polypeptides in the APPS structure.

In this paper we develop the analysis of the vibrational spectrum of (Gly I) ${ }_{n}$. We consider first the arguments, particularly spectroscopic, that favor the rippled-sheet structure. The latter include discussions of transition dipole coupling in amide I and amide II modes, as well as a consideration of the amide A, B, and V modes and of the low-frequency region. By obtaining agreement with observation in such diverse aspects of the spectrum, as well as by achieving transferability to other $\beta$ polypeptides, we increase significantly the reliability of our potential function. We then present the force field in detail and discuss its predictions of optically active frequencies.

\section{STRUCTURE OF CRYSTALLINE POLYGLYCINE I}

\section{Rippled-Sheet Polyglycine I}

As noted above, recent electron diffraction evidence ${ }^{10}$ suggests that (Gly I ${ }_{n}$ adopts a rippled-rather than a pleated-sheet structure. This proposal has also been supported by conformational energy calculations. ${ }^{12}$ We consider first the nature of this structure, using the APPS structure as a starting point.

The chain parameters used for APPS (Gly I) ${ }_{n}$ are given in Table I. With these values the $180^{\circ}$ helix with given $h$ (= repeat/residue) is adequate to completely describe the geometry of a single chain. However, in an antiparallel chain sheet with two chains per unit cell the orientation of the chains with respect to the sheet $(\alpha)$ and the relative axial shift of the chains with respect to one another (defined as $\Delta b$ ) must also be specified.

The orientation of the first chain with respect to the sheet is defined in terms of an angle $\alpha .{ }^{12}$ The axis of the first chain is taken to be the $b$-direction, the sheet being in the $a, b$ plane. If $\mathrm{C}_{1}^{\alpha}$, the first alpha carbon of the first chain, lies in the $a, c$ plane, and the next alpha carbon of the same chain is designated $\mathrm{C}_{2}^{\alpha}$, then the angle $\alpha$ is the acute angle between the $a$-axis and the projection on the $a, c$ plane of the line that connects $C_{1}^{\alpha}$ and $C_{2}^{\alpha}$. The second chain of the pleated sheet is generated by a $180^{\circ}$ rotation of chain 1 around the $c$-axis, an $a$-translation of magnitude $a / 2$, and a displacement 
TABLE I

Structural Parameters of Crystalline Polyglycine I

Chain Parameters ${ }^{3}$

$$
\begin{array}{rll}
\text { Bond lengths (in ångström): } & r\left(\mathrm{C}^{\alpha}-\mathrm{C}\right)=1.53 & r(\mathrm{C}=\mathrm{O})=1.24 \\
& r(\mathrm{C}-\mathrm{N})=1.32 & r(\mathrm{C} \alpha-\mathrm{H})=1.07 \\
& r\left(\mathrm{~N}-\mathrm{C}^{\alpha}\right)=1.47 & r(\mathrm{~N}-\mathrm{H})=1.00 \\
\text { Bond angles: } & \mathrm{C}^{\alpha} \mathrm{CN}=114^{\circ} & \mathrm{C}^{\alpha} \mathrm{CO}=121^{\circ} \\
& \mathrm{CNC}^{\alpha}=123^{\circ} & \mathrm{CNH}=123^{\circ} \\
& \mathrm{NC}^{\alpha} \mathrm{C}=\mathrm{NC}^{\alpha} \mathrm{H}=\mathrm{CC}^{\alpha} \mathrm{H}=\text { tetrahedral }
\end{array}
$$

Sheet Parameters

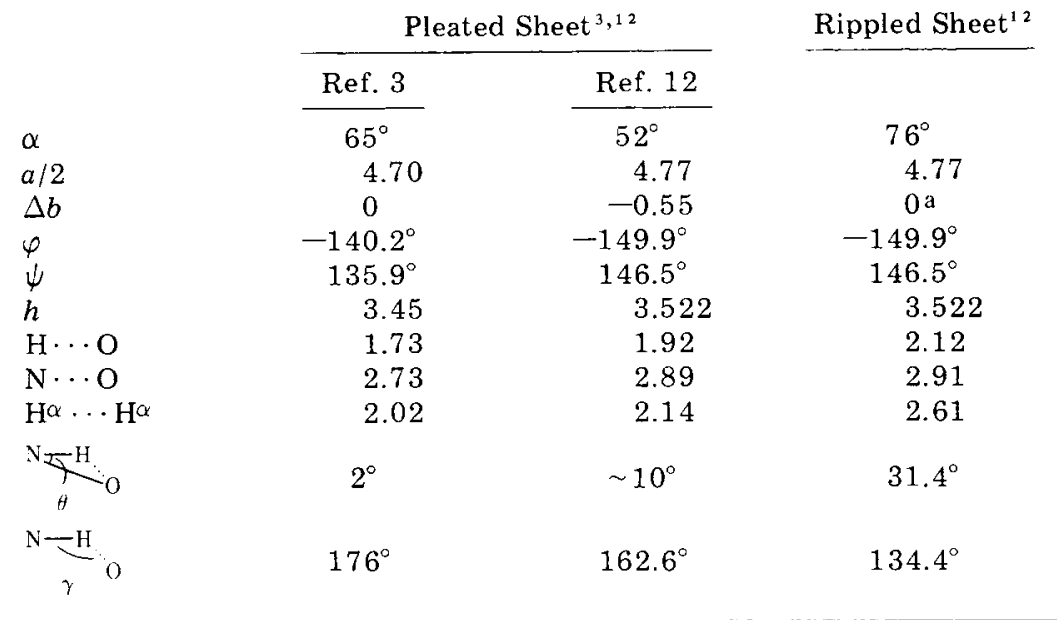

a From electron diffraction analysis. ${ }^{10}$ Energy calculations suggest $\Delta b=-0.7$.

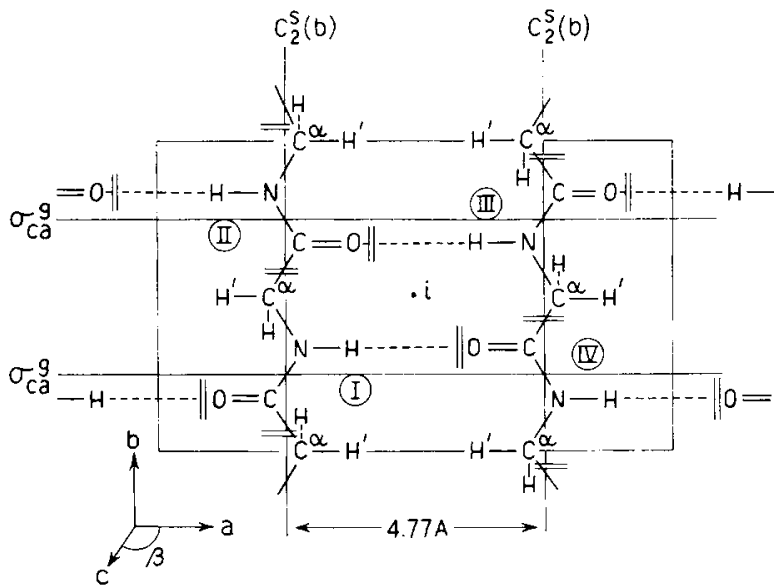

A.

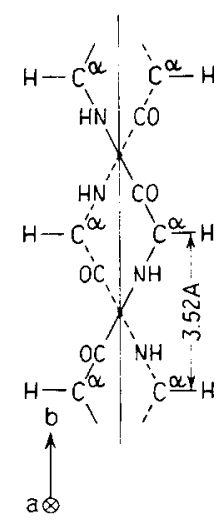

B.

Fig. 1. Antiparallel chain-rippled sheet structure of polyglycine I. (A) Projected on the $a, b$ plane. (B) Projected on the $b, c$ plane. 
TABLE II

Internal and Symmetry Coordinates for One Peptide Group of Polyglycine I

A. Internal Coordinates

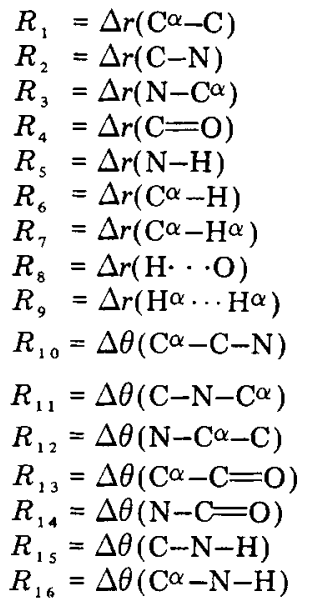

$$
\begin{aligned}
& R_{17}=\Delta \theta\left(\mathrm{N}-\mathrm{C}^{\alpha}-\mathrm{H}^{\prime}\right) \\
& R_{18}=\Delta \theta\left(\mathrm{N}-\mathrm{C}^{\alpha}-\mathrm{H}^{\prime}\right) \\
& R_{19}=\Delta \theta\left(\mathrm{C}-\mathrm{C}^{\alpha}-\mathrm{H}^{\prime}\right. \\
& R_{20}=\Delta \theta\left(\mathrm{C}-\mathrm{C}^{\alpha}-\mathrm{H}^{\prime}\right) \\
& R_{21}=\Delta \theta\left(\mathrm{H}-\mathrm{C}^{\alpha}-\mathrm{H}^{\prime}\right) \\
& R_{22}=\Delta \theta(\mathrm{C}=\mathrm{O} \cdots \mathrm{H}) \\
& R_{23}=\Delta \tau(\mathrm{C}=\mathrm{O} \cdots \mathrm{H}) \\
& R_{24}=\Delta \theta(\mathrm{N}-\mathrm{H} \cdots \mathrm{O}) \\
& R_{25}=\Delta \tau(\mathrm{N}-\mathrm{H} \cdots \mathrm{O}) \\
& R_{26}=\Delta \omega\left(\mathrm{O}=\mathrm{C}<_{\mathrm{C}}{ }^{\alpha}\right) \\
& R_{27}=\Delta \omega\left(\mathrm{H}-\mathrm{N}<C_{\mathrm{C}^{\alpha}}\right) \\
& R_{28}=\Delta \tau(\mathrm{C}-\mathrm{C}) \\
& R_{29}=\Delta \tau(\mathrm{C}-\mathrm{N}) \\
& R_{30}=\Delta \tau\left(\mathrm{N}-\mathrm{C}^{\alpha}\right)
\end{aligned}
$$

\section{B. Local Symmetry Coordinates}

$\begin{array}{ll}S_{1}=R_{3} & \mathrm{~N}-\mathrm{C} \alpha \text { stretch } \\ S_{2}=R_{1} & \text { C }-\mathrm{C} \text { stretch } \\ S_{3}=R_{2} & \mathrm{C}-\mathrm{N} \text { stretch } \\ S_{4}=R_{4} & \mathrm{C}=\mathrm{O} \text { stretch } \\ S_{5}=R_{5} & \mathrm{~N}-\mathrm{H} \text { stretch } \\ S_{6}=\left(R_{6}+R_{7}\right) / 2^{1 / 2} & \mathrm{CH} \text { symmetric stretch } \\ S_{1}=\left(R_{6}-R_{7}\right) / 2^{1 / 2} & \mathrm{CH}_{2} \text { asymmetric stretch } \\ S_{8}=\left(2 R_{10}-R_{14}-R_{15}\right) / 6^{1 / 2} & \mathrm{CNC} \text { deformation } \\ S_{9}=\left(5 R_{11}-R_{16}-R_{17}-R_{18}-R_{19}-R_{20}\right) / 30^{1 / 2} & \mathrm{NC} \alpha \text { deformation } \\ S_{10}=\left(2 R_{9}-R_{12}-R_{13}\right) / 6^{1 / 2} & \mathrm{C} \alpha \mathrm{CN} \text { deformation } \\ S_{11}=\left(R_{12}-R_{13}\right) / 2^{1 / 2} & \mathrm{C}=\mathrm{O} \text { ip bend } \\ S_{12}=\left(R_{14}-R_{15}\right) / 2^{1 / 2} & \mathrm{~N}-\mathrm{H} \text { ip bend } \\ S_{13}=\left(4 R_{20}-R_{16}-R_{17}-R_{18}-R_{19}\right) / 20^{1 / 2} & \mathrm{CH} \text { bend } \\ S_{14}=\left(R_{16}+R_{17}-R_{18}-R_{19}\right) / 2 & \mathrm{CH} \text { wag } \\ S_{15}=\left(R_{16}-R_{17}-R_{18}+R_{19}\right) / 2 & \mathrm{CH} \text { twist } \\ S_{16}=\left(R_{16}-R_{17}+R_{18}-R_{19}\right) / 2 & \mathrm{CH} \text { rock } \\ S_{17}=R_{25} & \mathrm{C}=\mathrm{O} \text { op bend } \\ S_{18}=R_{26} & \mathrm{~N}-\mathrm{H} \text { op bend } \\ S_{19}=R_{29} & \mathrm{~N}-\mathrm{C} \alpha \text { torsion } \\ S_{20}=R_{27} & \mathrm{C}-\mathrm{C} \text { torsion } \\ S_{21}=R_{28} & \mathrm{C}-\mathrm{N} \text { torsion } \\ S_{22}=R_{8} & \mathrm{H} \cdots \text { O stretch } \\ S_{23}=R_{21} & \mathrm{C}=\mathrm{O} \text { - bend } \\ S_{24}=R_{22} & \mathrm{C}=\mathrm{O} \text { torsion } \\ S_{25}=R_{23} & \mathrm{~N}-\mathrm{H} \text { - O bend } \\ S_{26}=R_{24} & \mathrm{~N}-\mathrm{H} \text { torsion } \\ S_{1}= & \end{array}$

a Here ip denotes vibrations in the plane of the amide group and op denotes those perperdicular to this plane. 


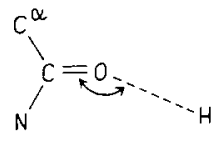

$\Delta \theta(C=0---h)$

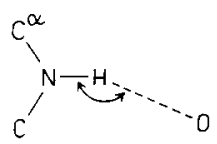

$\Delta \theta(\mathrm{N}-\mathrm{H}--\mathrm{O})$

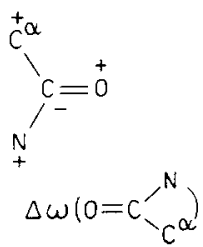

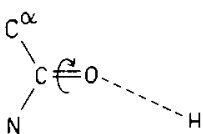

$\Delta \tau(C=0)$

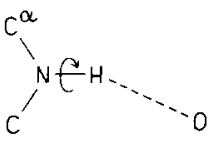

$\Delta \tau(N-H)$

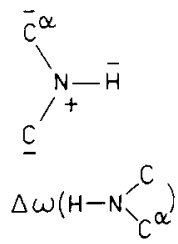

Fig. 2. Definitions of positive directions of some internal coordinates.

in the $b$-direction of magnitude $\Delta b$. The second chain of the rippled sheet is generated by one more operation, a reflection through the $a, b$ plane. The rippled-sheet structure is shown in Figure 1, and its parameters are given in Table I.

The sheet parameters $\alpha, a / 2$, and $\Delta b$ for several (Gly I) ${ }_{n}$ structures are given in Table II. Other parameters that identify the intermolecular geometry, such as $\tau\left(\mathrm{NC}^{\alpha}\right)=\varphi$ and $\tau\left(\mathrm{C}^{\alpha} \mathrm{C}\right)=\psi$, are also given. The structure used by Abe and $\mathrm{Krimm}^{3}$ in their normal vibration analysis of APPS (Gly $\mathrm{I})_{n}$ is characterized by short linear hydrogen bonds $(\mathrm{H} \ldots \mathrm{O} \cong 1.73 \AA, \mathrm{NH} \ldots \mathrm{O}$ $\left.\cong 176^{\circ}\right)$. The preferred APRS structure $\mathrm{e}^{10,12}$ is geometrically just the opposite, i.e., its hydrogen bonds are long and nonlinear $(\mathrm{H} \ldots \mathrm{O}=2.12 \AA$, $\mathrm{NH} \cdots \mathrm{O}=134.4^{\circ}$ ). Data on one of the pleated-sheet structures that is said to be energetically preferred ${ }^{12}$ are also tabulated.

The internal coordinates associated with a single peptide group are given in Table IIA, the definitions of the positive directions of some of these coordinates being shown in Figure 2. When the $\mathrm{N}-\mathrm{H} \cdots \mathrm{O}=\mathrm{C}$ geometry is nonlinear, the intermolecular coordinates $\mathrm{N}-\mathrm{H} \ldots \mathrm{O}$ in-plane bend, $\mathrm{N}-\mathrm{H}$... $\mathrm{O}$ out-of-plane bend, $\mathrm{C}=\mathrm{O} \ldots \mathrm{H}$ in-plane bend, and $\mathrm{C}=\mathrm{O} \ldots \mathrm{H}$ out-of-plane bend are replaced by an $\mathrm{N}-\mathrm{H} . . . \mathrm{O}$ bend, a $\mathrm{C}=\mathrm{O} \ldots \mathrm{H}$ bend, an $\mathrm{N}-\mathrm{H}$ torsion, and a $\mathrm{C}=\mathrm{O}$ torsion. In the pleated sheet, with $D_{2}$ symmetry, the optically active symmetry coordinates are classified into $A, B_{1}, B_{2}$, and $B_{3}$ symmetry species. The rippled-sheet structure has $\mathrm{C}_{2 h}$ symmetry. Therefore, two of its four symmetry species are only ir active and two are only Raman ac- 
TABLE III

Symmetry Species and Selection Rules for Crystalline Polyglycine I

\begin{tabular}{|c|c|c|c|c|c|c|c|}
\hline \multirow{2}{*}{$\begin{array}{l}\text { Species } \\
\begin{array}{l}\text { Pleated } \\
\text { Sheet }\end{array}\end{array}$} & \multirow[t]{2}{*}{$\nu\left(\delta, \delta^{\prime}\right)$} & \multicolumn{3}{|c|}{ Symmetry } & \multirow[t]{2}{*}{$\begin{array}{c}\text { Number } \\
\text { of } \\
\text { Modes }\end{array}$} & \multirow[t]{2}{*}{ Activity ${ }^{a}$} & \multirow[t]{2}{*}{$\begin{array}{c}\text { Lattice } \\
\text { Vibra- } \\
\text { tions }{ }^{b}\end{array}$} \\
\hline & & $\mathrm{C}_{2}^{s}(\mathrm{a})$ & $\mathrm{C}_{2}^{s}(\mathrm{~b})$ & $\mathrm{C}_{2}(\mathrm{c})$ & & & \\
\hline A & $\nu(0,0)$ & 1 & 1 & 1 & 21 & $\mathrm{R}$ & $R, T_{b}$ \\
\hline$B_{1}$ & $\nu(0, \pi)$ & -1 & 1 & -1 & 20 & $R$, ir $(\|)$ & $R$ \\
\hline$B_{2}$ & $\nu(\pi, 0)$ & 1 & -1 & -1 & 20 & $R, \operatorname{ir}(\perp)$ & $T_{c}$ \\
\hline $\begin{array}{c}B_{3} \\
\text { Ripoled }\end{array}$ & $\nu(\pi, \pi)$ & -1 & -1 & 1 & 20 & $R, \operatorname{ir}(1)$ & $T_{a}$ \\
\hline Sheet & & $\mathrm{C}_{2}{ }^{s}(\mathrm{~b})$ & $i$ & $\sigma_{c a} g$ & & & \\
\hline$A_{g}$ & $\nu(0,0)$ & 1 & 1 & 1 & 21 & $\mathrm{R}$ & $R, T_{b}$ \\
\hline$A_{u}^{\circ}$ & $\nu(0, \pi)$ & 1 & -1 & -1 & 20 & ir (li) & $R$ \\
\hline$B_{u}$ & $\nu(\pi, 0)$ & -1 & -1 & 1 & 19 & $\operatorname{ir}(1)$ & - \\
\hline$B_{g}$ & $\nu(\pi, \pi)$ & -1 & 1 & -1 & 21 & $\mathrm{R}$ & $T_{a}, T_{c}$ \\
\hline
\end{tabular}

a $R=$ Raman, ir = infrared.

b $R=$ rotatory, $T=$ translatory modes.

tive. The symmetry coordinates for each species are constructed as follows:

Pleated Rippled

$$
\begin{aligned}
& S(A) \rightarrow C \sum_{i}\left(S_{\mathrm{I}}^{i}+S_{\mathrm{II}}^{i}+S_{\mathrm{III}}^{i}+S_{\mathrm{IV}}^{i}\right) \leftarrow S\left(A_{g}\right) \\
& S\left(B_{1}\right) \rightarrow C \sum_{i}\left(S_{\mathrm{I}}^{i}+S_{\mathrm{II}}^{i}-S_{\mathrm{III}}^{i}-S_{\mathrm{IV}}^{i}\right) \leftarrow S\left(A_{u}\right) \\
& S\left(B_{2}\right) \rightarrow C \sum_{i}\left(S_{\mathrm{I}}^{i}-S_{\mathrm{II}}^{i}-S_{\mathrm{III}}^{i}+S_{\mathrm{IV}}^{i}\right) \leftarrow S\left(B_{u}\right) \\
& S\left(B_{3}\right) \rightarrow C \sum_{i}\left(S_{\mathrm{I}}^{i}-S_{\mathrm{II}}^{i}+S_{\mathrm{III}}^{i}-S_{\mathrm{IV}}^{i}\right) \leftarrow S\left(B_{g}\right)
\end{aligned}
$$

where the $S_{\mathrm{I}}, S_{\mathrm{II}}, S_{\mathrm{III}}, S_{\mathrm{IV}}$ refer to the local symmetry coordinates of each peptide group of the unit cell (Table IIB), and $C$ is a normalization constant.

The optical activity, dichroic behavior, number of normal modes, and types of lattice modes in each symmetry species are given in Table III.

\section{Spectroscopic Evidence for Rippled-Sheet Polyglycine I}

Several features of the (Gly I) ${ }_{n}$ spectra are better explained by assuming that the sheet structure is rippled rather than pleated. These are: the splitting of the components of amide I, the low frequency of the $\mathrm{N}-\mathrm{H}$ inplane bending mode (amide II), the relatively high unperturbed frequency 
associated with $\mathrm{N}-\mathrm{H}$ stretching, the shift of amide $\mathrm{V}$ in $\mathrm{N}$-deuterated (Gly I) $n$, and the Raman and ir bands below $200 \mathrm{~cm}^{-1}$.

Amide I Modes. The observed splittings between the components of the amide I vibrations in polyamides and polypeptides are known to provide information concerning both the intrachain and interchain geometry. In order to explain these splittings, a perturbation treatment of the interactions between peptide groups in polypeptides was developed by Miyazawa. ${ }^{13,14}$ Subsequently, Abe and Krimm ${ }^{3,6}$ demonstrated that in (Gly I) ${ }_{n}$ the perturbation terms required by the Miyazawa treatment could not be reproduced by a general valence force field, and that these splittings could be explained in a normal vibration analysis if transition dipole coupling were assumed to provide the physical basis for part of the observed splittings. Moore and Krimm ${ }^{5,11}$ encountered difficulties in using this theory of transition dipole coupling to predict the observed amide I bands in polypeptides that contain beta carbon atoms, such as poly(L-alanine) $\left[(\mathrm{Ala})_{n}\right]$, poly (L-alanylglycine) $\left[(\mathrm{Ala}-\mathrm{Gly})_{n}\right]$, and poly(L-valine $)\left[(\mathrm{Val})_{n}\right]$ : namely, the location of the transition dipole center and the orientation and magnitude of the transition dipole moment were not consistent with the magnitude of these parameters in (Gly I $)_{n}$. These difficulties were not found for calculations that assumed a rippled-sheet structure for (Gly $\mathrm{I})_{n}$ and a pleated-sheet structure for the other polypeptides. ${ }^{7}$ In this successful calculation, the contributions to the amide I frequency shifts were assumed to be due to the interaction, through transition dipole coupling, of each peptide group with its six nearest neighbors, two on the same chain and two on each of the two adjacent chains. ${ }^{7}$ The maximum circle of influence in this calculation had a radius $R=5 \AA$.

Chirgadze and Nevskaya ${ }^{15}$ accepted this coupling mechanism as being responsible for the observed amide I splittings, and suggested that the effective circle of influence in a transition dipole coupling calculation should be extended to $10 \AA \leq R \leq 30 \AA$. Our calculations showed this recommendation to be a good one. ${ }^{7}$ In addition, we now find that the circle of influence should become a sphere of influence, i.e., contributions to frequency shifts from adjacent sheets must also be considered.

In the APPS (Gly I) ${ }_{n}$ structure adjacent sheets are displaced by $3.55 \AA$ and $2.385 \AA$ along the $c$ - and $a$-axes, respectively. For the rippled sheet these parameters are $3.55 \AA$ and $1.65 \AA$, respectively. ${ }^{12}$ Since for both structures there are contributions from an interaction sphere of $R \geq 4.5$ $\AA$, our present results incorporate intrasheet and intersheet interactions.

In applying this generalized transition dipole coupling approach to $\beta$ polypeptide structures, the frequency of a given normal mode is represented by

$$
\nu\left(\delta, \delta^{\prime}\right)=\nu_{0}^{\prime}+\sum_{s, t, u} D_{s, t, u}^{\prime} \cos (s \delta) \cos \left(t \delta^{\prime}\right)
$$




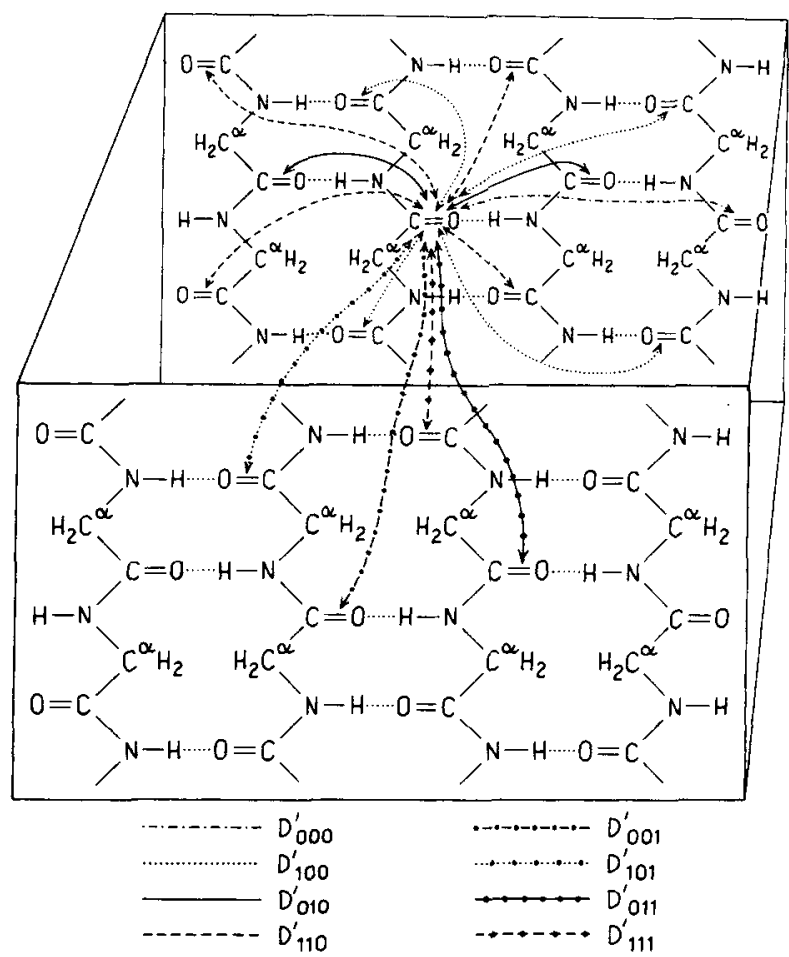

Fig. 3. Transition dipole coupling interaction terms in crystalline polyglycine I.

This expression can be meaningfully written as

$$
\begin{aligned}
\nu\left(\delta, \delta^{\prime}\right)=\nu_{0}^{\prime}+\sum_{s, t, u} & {\left[D_{2 s, 2 t, u}^{\prime}+D_{2 s+1,2 t, u}^{\prime} \cos (s \delta)\right.} \\
+ & \left.D_{2 s, 2 t+1, u}^{\prime} \cos \left(t \delta^{\prime}\right)+D_{2 s+1,2 t+1, u}^{\prime} \cos (s \delta) \cos \left(t \delta^{\prime}\right)\right]
\end{aligned}
$$

where $\nu_{0}^{\prime}$ is the unperturbed frequency of a normal mode of a peptide group, and $\delta, \delta^{\prime}$ are the phase angles between the normal modes of vibration of adjacent peptide groups on a given chain and between hydrogen bonded peptide groups on adjacent chains, respectively. When peptide groups are in a sheet that is not coincident with the sheet of the $t=0$ chain of the reference sheet, the chain with the same sense (i.e., up or down) and geometrically closest to the reference chain is called the $t=0$ chain of sheet $u$. In terms of previous notation, $D_{s, t, u}^{\prime}$ is the interaction constant between two peptide groups separated by $u$ sheets, $t$ chains, and $s$ groups along the $t$ th chain.

For the antiparallel chain sheet we can represent the perturbation equations as:

$$
\nu\left(\delta, \delta^{\prime}\right)=\nu_{0}^{\prime}+D_{00}+D_{10} \cos \delta+D_{01} \cos \delta^{\prime}+D_{11} \cos \delta \cos \delta^{\prime}
$$

where the unprimed $D$ 's now represent the result of summing Eq. (1) over all equivalent peptide groups (cf. Fig. 3). Because there are four peptide 
groups in a unit cell of the antiparallel sheet (identified in Fig. 1 as groups I, II, III, and IV), the terms in Eq. (3) can be referred to these four groups. If, for example, we are calculating the frequency shift induced in the amide I vibration of group II, then the $D_{00}$ term is the sum of all contributions (in $\mathrm{cm}^{-1}$ ) to the dipole-dipole interaction due to those peptide groups that are geometrically obtainable by pure translations of group II. $D_{00}$ is therefore not phase dependent. Similarly, $D_{10}, D_{01}$, and $D_{11}$ are the summation of perturbation contributions to group II from all peptide groups within the crystal that are geometrically obtained by pure translations of groups I, III, and IV, respectively. (Note that in the present treatment we do not assume, as was originally done for the single sheet, ${ }^{3,6}$ that $D_{10}=0$.)

The change in potential energy due to any two interacting dipoles is given by:

$$
\Delta V=\frac{1}{\epsilon}\left|\frac{\partial \mu_{1}}{\partial S_{1}}\right|\left|\frac{\partial \mu_{2}}{\partial S_{2}}\right| \Delta S_{1} \Delta S_{2} \frac{(\cos \alpha-3 \cos \beta \cos \gamma)}{|R|^{3}}(\mathrm{erg})
$$

When $R$ and $\Delta S$ are in ångström, and $\partial \mu / \partial S$ is in $D / \AA$, the frequency shift associated with this additional potential energy is (for $\epsilon=1$ )

$$
\Delta \nu=D_{m n}^{\prime}=5.035 \times 10^{3}\left(\frac{\partial \mu_{m}}{\partial S_{m}}\right)\left(\frac{\partial \mu_{n}}{\partial S_{n}}\right) \Delta S_{m} \Delta S_{n} X_{m n}=N X_{m n}\left(\mathrm{~cm}^{-1}\right)
$$

Since for the antiparallel chain sheet

$$
\begin{aligned}
& \nu(0,0)=\nu_{0}^{\prime}+D_{00}+D_{10}+D_{01}+D_{11}+c_{1} \\
& \nu(0, \pi)=\nu_{0}+D_{00}+D_{10}-D_{01}-D_{11}+c_{1} \\
& \nu(\pi, 0)=\nu_{0}+D_{00}-D_{10}+D_{01}-D_{11}-c_{1} \\
& \nu(\pi, \pi)=\nu_{0}+D_{00}-D_{10}-D_{01}+D_{11}-c_{1}
\end{aligned}
$$

where $c_{1}$ is the contribution of the valence force field alone (of the order of $1 \mathrm{~cm}^{-1}$ for amide I modes ${ }^{6}$, we can specifically represent the frequency splittings, $\Delta \nu$, between the various symmetry species, as

$$
\begin{aligned}
& \nu(0,0)-\nu(0, \pi)=2 N\left(X_{01}+X_{11}\right)=2\left(D_{01}+D_{11}\right) \\
& \nu(0, \pi)-\nu(\pi, 0)=2 N\left(X_{10}-X_{01}\right)+2 c_{1}=2\left(D_{10}-D_{01}\right)+2 c_{1} \\
& \nu(0,0)-\nu(\pi, 0)=2 N\left(X_{10}+X_{11}\right)+2 c_{1}=2\left(D_{10}+D_{11}\right)+2 c_{1}
\end{aligned}
$$

Differences involving $\nu(\pi, \pi)$ are not included because this frequency is not generally observed. Since only two of the three relationships in Eqs (7) are independent, we can formulate only two independent ratios for comparison with experimental observations, for example

$$
\begin{aligned}
& \text { ratio } 1=\frac{X_{01}+X_{11}}{X_{10}-X_{01}}=\frac{\nu(0,0)-\nu(0, \pi)}{\nu(0, \pi)-\nu(\pi, 0)-2 c_{1}} \\
& \text { ratio } 2=\frac{X_{10}+X_{11}}{X_{10}-X_{01}}=\frac{\nu(0,0)-\nu(\pi, 0)-2 c_{1}}{\nu(0, \pi)-\nu(\pi, 0)-2 c_{1}}
\end{aligned}
$$


TABLE IV

Values of Ratios [Eq. (8)] as a Function of $\Delta b$ for Crystalline Polyglycine I

\begin{tabular}{ccccc}
\hline & \multicolumn{2}{c}{ Rippled Sheet } & \multicolumn{2}{c}{ Pleated Sheet } \\
$\Delta b(\AA)$ & Ratio 1 & Ratio 2 & Ratio 1 & Ratio 2 \\
\hline 0.0 & -0.24 & 0.77 & -0.40 & 0.60 \\
-0.1 & -0.30 & 0.70 & -0.48 & 0.52 \\
-0.2 & -0.38 & 0.62 & -0.60 & 0.40 \\
-0.3 & -0.45 & 0.55 & -0.65 & 0.35 \\
-0.4 & -0.51 & 0.49 & -0.70 & 0.30 \\
-0.5 & -0.57 & 0.41 & -0.70 & 0.30 \\
-0.6 & -0.62 & 0.38 & -0.74 & 0.26 \\
-0.7 & -0.66 & 0.34 & -0.78 & 0.23 \\
\hline
\end{tabular}

Observed: ratio $1=-0.244 ;$ ratio $2=0.755$

The parameters needed to calculate the geometric factors, $X_{m n}$, for a given polypeptide are the crystal structure and the orientation and location of the center of the transition dipole moment. Sandeman ${ }^{16}$ and Suzuki ${ }^{17}$ determined the orientation angle from measurements of the polarization and intensity of ir amide I bands. They found that the transition dipole moment is inclined about $20^{\circ}$ from the $\mathrm{C}=0$ bond direction towards the $\mathrm{N} \rightarrow \mathrm{C}$ direction. From normal vibration calculations, and the resulting determination of the atomic motions associated with the amide I vibrations, we know that this mode is mainly localized in the motions of the $\mathrm{O}, \mathrm{C}$, and $\mathrm{N}$ atoms. The amide I mode is in fact dominated by the stretching of the $\mathrm{C}=\mathrm{O}$ bond, which contributes five times more to the potential energy than does any other local coordinate. Since $\mathrm{C}=\mathrm{O}$ stretching is dominated by the electrical properties of the highly electronegative oxygen atom, we would expect the transition dipole moment of amide I to be close to the oxygen and in the $\mathrm{O}-\mathrm{C}-\mathrm{N}$ plane. Because the eigenvectors and potential energy distributions for amide I of (Gly I) $n$ and (Ala) ${ }_{n}$ (as well as other $\beta$ polypeptides) are almost identical, ${ }^{7}$ we have assumed that the transition dipole moments: 1) have the same orientation relative to $\mathrm{C}=0,2$ ) have their centers at the same location relative to the $\mathrm{C}=\mathrm{O}$ bond, and 3 ) should have magnitudes that are very nearly equal.

As before, ${ }^{7}$ we have calculated the values of ratio 1 and ratio 2 for a range of values of the transition dipole location and orientation, and of $\Delta b$. The range of interaction was $\pm 35 \AA$ within a sheet and \pm 3 sheets. It was found that the best agreement is obtained for an orientation angle of $20^{\circ}$, in good agreement with experiment. ${ }^{16,17}$ The calculated values of the ratios for rippled and pleated sheets are given in Table IV. The observed values are: ratio $1=-0.244$, ratio $2=0.755$. The best location of the transition moment center along the $\mathrm{C}=\mathrm{O}$ bond was found to be $0.868 \AA$ from the carbon atom. We note that for the pleated-sheet structure there are no values of $\Delta b$ for which the predicted and observed ratios are even close (positive values of $\Delta b$ are excluded because of unfavorable steric and electrostatic interactions). For the rippled-sheet structure the correct relationships 
are predicted for $\Delta b \cong 0.0$, which is exactly the axial shift indicated by the electron diffraction analysis. ${ }^{10}$

The actual values of the interaction constants and the amide I frequencies implied by these results are given in Table V. Note that $D_{10}$ for APRS (Gly I) $n$ is not approximately zero, as had been indicated by earlier sheet calculations. ${ }^{3,6}$ This is a result of our summation over adjacent sheets and of their close approach in $(\text { Gly I })_{n}$. Miyazawa ${ }^{13,14}$ originally predicted a large positive value for the $D_{10}$ interaction term. However, the observed $\nu(0, \pi)-\nu(\pi, 0)=2\left(D_{10}-D_{01}\right)$ splitting decreases by $20-30 \mathrm{~cm}^{-1}$ from (Gly I) $n$ to nylon-10.18 Although we do not know the specific value of the $D_{01}$ term in the nylons, the fact that in nylon- $2 n$ the $D_{10}$ term approaches zero as $n$ increases will account for an $\sim 15 \mathrm{~cm}^{-1}$ reduction in the observed ir splitting.

We are also interested in how these predicted splittings can be reproduced in a normal vibration calculation. The potential energy associated with a given normal mode can always be represented as

$$
2 V=\frac{\partial^{2} V}{\partial S_{m m}^{2}} \Delta S_{m} \Delta S_{m}=F_{m m}^{\prime \prime} \Delta S_{m}^{2}
$$

where $\Delta S_{m}$ is the normal coordinate of normal mode $\nu_{m}$. From the Jacobian of such a normal vibration calculation we can also obtain the value of $\partial \nu_{m} / \partial F_{m m}$, and therefore the change of the total frequency due to a force constant change.

In the presence of transition dipole coupling the valence force field diagonal force constant associated with each symmetry block, $F_{m m}^{\prime}$, is changed. Thus,

$$
\begin{aligned}
& F_{m m}^{v(0,0)}=F_{m m}^{\prime}+F_{\mathrm{II}, \mathrm{I}}+F_{\mathrm{II}, \mathrm{III}}+F_{\mathrm{II}, \mathrm{IV}} \\
& F_{m m}^{\nu(0, \pi)}=F_{m m}^{\prime}+F_{\mathrm{II}, \mathrm{I}}-F_{\mathrm{II}, \mathrm{III}}-F_{\mathrm{II}, \mathrm{IV}} \\
& F_{m m}^{\nu(\pi, 0)}=F_{m m}^{\prime}-F_{\mathrm{II}, \mathrm{I}}+F_{\mathrm{II}, \mathrm{III}}-F_{\mathrm{II}, \mathrm{IV}} \\
& F_{m m}^{\nu(\pi, \pi)}=F_{m m}^{\prime}-F_{\mathrm{II}, \mathrm{I}}-F_{\mathrm{II}, \mathrm{III}}+F_{\mathrm{II}, \mathrm{IV}}
\end{aligned}
$$

The magnitudes of $F_{\mathrm{II}, \mathrm{I}}, F_{\mathrm{II}, \mathrm{III}}$, and $F_{\mathrm{II}, \mathrm{IV}}$, namely

$$
F_{i j}=(0.1)\left(\frac{\partial \mu_{m}}{\partial S_{m}}\right)_{\substack{\text { peptidie } \\ \text { groups }}}^{2}\left(\frac{\cos \alpha-3 \cos \beta \cos \gamma}{R^{3}}\right)_{i, j}
$$

are related to the interaction constants obtained from transition dipole coupling by:

$$
D_{i j}=\frac{\partial \nu_{m}}{\partial F_{m m}} F_{i j}
$$

If $\partial \nu_{m} / \partial F_{m m}$ were known, we could determine the magnitude of the transition dipole moment, $\left(\partial \mu_{m} / \partial S_{m}\right)$, from Eqs. (11) and (12).

Normal vibration calculations, however, are not formulated in terms of 
TABLE V

Amide I Frequencies and Interaction Constants (in $\mathrm{cm}^{-1}$ ) for Crystalline Polyglycine I

\begin{tabular}{lll}
\hline & Pleated Sheet & \multicolumn{1}{c}{ Rippled Sheet } \\
\hline$\nu(0,0)$ & 1676 & 1674 [observed: 1674$]$ \\
$\nu(0, \pi)$ & 1701 & 1685 [observed: 1685$]$ \\
$\nu(\pi, 0)$ & 1636 & 1637 [observed: 1636 ] \\
$\nu(\pi, \pi)$ & 1691 & 1690 \\
$D_{10}$ & $12.53\left(F_{10}=0.189 \mathrm{a}\right)$ & $7.91\left(F_{10}=0.102\right)$ \\
$D_{01}$ & $-19.78\left(F_{01}=-0.300\right)$ & $-16.10\left(F_{01}=-0.244\right)$ \\
$D_{11}$ & $7.37\left(F_{11}=0.112\right)$ & $10.55\left(F_{11}=0.160\right)$ \\
$D_{00}$ & {$[$ not calculated } & -6.1 \\
$\nu_{0} \mathrm{~b}$ & 1676.2 & 1671.6 \\
$\Delta \mu_{\mathrm{eff}} \mathrm{c}$ & $0.330 \mathrm{D}$ & $0.348 \mathrm{D}$ \\
\hline
\end{tabular}

${ }^{a}$ From Eq. (13) (see text).

$\mathrm{b}_{0}=\nu_{0}^{\prime}+D_{00}$.

c $\Delta \mu_{\mathrm{eff}}=(\partial \mu / \partial S) \Delta S$.

normal coordinates, but in terms of local symmetry coordinates. Therefore, the magnitude of $\left(\partial \mu_{m} / \partial S_{m}\right)$ is not readily available to us. A way to reproduce the effects of transition dipole coupling in a normal vibration calculation is to introduce interaction force constants between the $\mathrm{C}=\mathrm{O}$ groups in a unit cell. The required magnitudes of these interaction force constants are given by

$$
F_{i j}=D_{i j} /\left(\partial \nu_{m} / \partial F_{\mathrm{C}=\mathrm{o}}\right)
$$

If $\partial \nu_{m} / \partial F_{\mathrm{C}=\mathrm{O}}=66$, a value obtained from the Jacobian matrix, the resulting $F_{i j}$ 's will make it possible to predict the observed splittings, but they do not yield a meaningful value of $\left(\partial \mu_{m} / \partial S_{m}\right)$ (particularly since $\epsilon$ is unknown). It is therefore useful to consider instead the quantity ( $\partial u / \partial S$ )$(\Delta S)$, which can be interpreted as the effective dipole moment, $\Delta \mu_{\mathrm{eff}}$, induced in a peptide group while it undergoes an amide I vibration. These values are also given in Table $\mathrm{V}$.

Amide II Modes. Amide II is due to combined N-H in-plane bending and $\mathrm{C}-\mathrm{N}$ stretching modes. Although there are four components of this mode in the antiparallel chain sheet, the strong band in the ir, $\nu(0, \pi)$, has

\section{TABLE VI}

The $\nu(0, \pi)$ Amide II Frequencies (in $\mathrm{cm}^{-1}$ ) for Various $\beta$ Polypeptides with Different Structures

\begin{tabular}{lcccc} 
& & \multicolumn{3}{c}{ Calculated $^{\mathrm{a}}$} \\
& Observed & 1 & 2 & 3 \\
\hline (Gly I $)_{n}$ & 1517 & 1510 & 1532 & 1517 \\
$(\text { Ala })_{n}$ & 1524 & 1510 & 1528 & 1528 \\
$(\text { Ala-Gly })_{n}$ & 1535 & 1515 & 1535 & 1535 \\
$(\text { Val })_{n}$ & 1536 & 1511 & 1533 & 1530 \\
\hline
\end{tabular}

a See text for explanation of structures. 
parallel dichroic behavior and is observed in known pleated-sheet polypeptides between $1524 \mathrm{~cm}^{-1}$ and $1537 \mathrm{~cm}^{-1}$. Note that this normal mode has its lowest frequency, $1517 \mathrm{~cm}^{-1}$, in $(\mathrm{Gly} \mathrm{I})_{n}$. Since the frequency difference between amide II of (Gly I) ${ }_{n}$ and (Ala) $)_{n}$ is only $7 \mathrm{~cm}^{-1}$, the low frequency of $(\mathrm{Gly} \mathrm{I})_{n}$ has never been recognized as anomalous.

In order to evaluate the sensitivity of amide II to structure, we have calculated the $\nu(0, \pi)$ frequency in (Gly I $)_{n},(\text { Ala })_{n},(\text { Ala-Gly })_{n}$, and $(\mathrm{Val})_{n}$ for several structural sheet models, using only a valence force field. The results are shown in Table VI. The $(\text { Gly } \mathrm{I})_{n}$ force field is that presented in this paper; the (Ala) ${ }_{n}$ force field is that given in the succeeding paper. ${ }^{19}$ In column 1 all of the polypeptides have the same APPS structure, that of Abe and Krimm. ${ }^{3}$ It is clear that poor agreement is achieved with the observed bands. For the calculations in column 2 the polypeptides had slightly different APPS structures: (Gly I) ${ }_{n}$ was that of the calculated minimum energy structure, ${ }^{12}$ (Ala $)_{n}$ was taken from the X-ray refinement, ${ }^{20}$ $(\text { Ala-Gly })_{n}$ was also taken from an X-ray study, ${ }^{21}$ and $(\mathrm{Val})_{n}$ was the same as before. ${ }^{3}$ The results for this case show that the predicted difference between (Ala) $)_{n}$ and (Gly I) $)_{n}$ has the incorrect sign, i.e., for (Gly I) ${ }_{n}$ the calculated frequency $\left(1532 \mathrm{~cm}^{-1}\right)$ is $4 \mathrm{~cm}^{-1}$ higher than the calculated frequency for (Ala $)_{n}\left(1528 \mathrm{~cm}^{-1}\right)$, whereas the observed (Gly I $)_{n}$ frequency $\left(1517 \mathrm{~cm}^{-1}\right)$ is $7 \mathrm{~cm}^{-1}$ lower than that of (Ala $)_{n}\left(1524 \mathrm{~cm}^{-1}\right)$. On the other hand, differences between (Ala $)_{n}$, (Ala-Gly $)_{n}$, and $(\mathrm{Val})_{n}$ are well accounted for. However, if we use the force constants that effectively predict amide II in APPS (Ala) ${ }_{n}$ in a normal vibration calculation, but take $(\text { Gly I })_{n}$ in the APRS structure, all amide II bands are in rather good agreement with observation (column 3).

Although the above analysis clearly favors an APRS structure for (Gly I) $n$, it is still necessary to inquire whether transition dipole coupling has a major effect on the observed differences between $\nu(0, \pi)$ amide II modes. If it does, the above conclusions might be fortuitous.

The apparent success that resulted from invoking transition dipole coupling to explain the amide I splittings observed in $\beta$ polypeptides would naturally suggest that this mechanism be applied to amide II vibrations. Although we believe that this coupling does cause splittings, the reader must be aware of important differences between amide I and amide II modes. The angle that the transition moment of amide I makes with a given reference, taken to be the $\mathrm{C}=\mathrm{O}$ bond, has been measured to be essentially constant for different symmetry species and polymers. In the amide II vibration this angle has been observed to vary by as much as $10^{\circ}$. For amide II the potential energy distributions are also less constant between symmetry species than is the case for amide $\mathrm{I}$.

We have, nevertheless, obtained interesting results by incorporating transition dipole coupling into a description of amide II modes. Our calculations assume that the transition dipole center is located on the $\mathrm{N}-\mathrm{H}$ bond. This seems reasonable since normal vibration calculations and the resulting atomic motions indicate that amide II involves an extremely large 
TABLE VII

Amide II Frequencies (in $\mathrm{cm}^{-1}$ ) of Polyglycine I and Poly(L-alanine) Calculated with Transition Dipole Coupling

\begin{tabular}{lcccc}
\hline & \multicolumn{2}{c}{ Polyglycine I } & \multicolumn{2}{c}{ Poly(L-Alanine) } \\
& Observed & Calculated & Observed & Calculated \\
\hline$\nu(0,0)$ & $1515(\mathrm{R})$ & 1515 & $1538(\mathrm{R})$ & 1534 \\
$\nu(0, \pi)$ & $1517(\mathrm{ir})$ & 1516 & $1524(\mathrm{ir})$ & 1523 \\
$\nu(\pi, 0)$ & & 1563 & $1555(\mathrm{R})$ & 1555 \\
$\nu(\pi, \pi)$ & & 1588 & & 1587 \\
$D_{10}$ & & -24.07 & & -15.77 \\
$D_{01}$ & & -6.43 & & -4.95 \\
$D_{11}$ & & 6.13 & & 11.04 \\
$D_{00}$ & & 2.9 & & -1.7 \\
$\nu_{0} \mathrm{a}$ & & 1545.8 & & 1550.0 \\
\hline
\end{tabular}

$\mathrm{a} \nu_{0}=\nu_{0}^{\prime}+D_{00}$.

displacement of the $\mathrm{H}$ atom of the $\mathrm{N}-\mathrm{H}$ bond. Because there is a considerable amount of $\mathrm{C}-\mathrm{N}$ stretching in amide II (approximately $30 \%$ ), the transition center is not constrained to be on the hydrogen atom. An optimization calculation places it $0.6 \AA$ towards the nitrogen atom. The angle toward $\mathrm{N} \rightarrow \mathrm{C}$ that the transition moment associated with amide II makes with the $\mathrm{C}=\mathrm{O}$ bond is taken to be $68^{\circ}$, a value observed by Sandeman. ${ }^{16}$ Chirgadze, et al. ${ }^{22}$ reported the intensities of amide II and amide I bands for polypeptides in the $\beta$ form. From their work we calculate the ratio of these intensities to be 0.532 , and this value was used to estimate the magnitude of the transition dipole moment of amide II. For example, for amide I of (Gly I $)_{n}$ the effective transition moment was calculated to be $\Delta \mu_{\text {eff }}=$ $0.348 D$ (see Table V). Since the observed intensity of a band is proportional to $\left(\Delta \mu_{\mathrm{eff}}\right)^{2}$, we obtain for amide II a $\Delta \mu_{\mathrm{eff}}=0.254 \mathrm{D}$. The results of the transition dipole coupling calculations are given in Table VII.

In instances where bands have been observed the agreement is quite respectable. Although a very weak Raman band has been reported for (Gly I) $n$ at $1564 \mathrm{~cm}^{-1}$, we do not assign this band to the $\nu(\pi, 0)$ amide II mode for two reasons: 1 ) in the rippled sheet the $\nu(\pi, 0)$ mode is not Raman active, and 2) Small et al., ${ }^{23}$ who observed this band, reported that a similar band also appeared in the Raman spectrum of $(\text { Gly II })_{n}$. Because this band remained unchanged in the deuterated spectra of (Gly II) ${ }_{n}$, it could not be assigned to amide II. From Table VII we see that the values for $\nu_{0}^{\prime}$ are essentially the frequencies that would be calculated for the $\nu(0, \pi)$ or $\nu(0,0)$ amide II modes in a normal vibration calculation that did not include transition dipole coupling. Note that the results on (Ala) ${ }_{n}$ and (Gly I) ${ }_{n}$ imply that in such a normal vibration calculation this frequency should be calculated $9 \mathrm{~cm}^{-1}$ higher in (Ala $)_{n}$ than in (Gly I $)_{n}$. Referring now to the amide II calculations in column 3 of Table VI, we note that an $11 \mathrm{~cm}^{-1}$ splitting is predicted by a normal vibration analysis without transition dipole coupling. We can, therefore, be confident that the analysis of the 
amide II modes clearly indicates that the APRS structure is the preferred one for (Gly I) .

Amide $A$ and $B$ Modes. Another positive feature that results from incorporating the effects of transition dipole coupling in the amide II modes is the predicted high value of the $\nu(\pi, \pi)$ frequency and its implications with respect to the amide $A$ and $B$ modes.

Amide A and amide B are the two bands that appear in the spectra of polypeptides at about $3300 \mathrm{~cm}^{-1}$ and $3100 \mathrm{~cm}^{-1}$, respectively. It is generally accepted that the higher of the two frequencies is due to the stretching of the $\mathrm{N}-\mathrm{H}$ bond. 'The lower frequency band has been assigned to the first overtone of the amide II mode undergoing intensity enhancement due to Fermi resonance with the $\mathrm{N}-\mathrm{H}$ stretching vibration. Tsuboi, ${ }^{24}$ however, showed that in APPS (Gly I) $n$ the first overtone of an amide II mode could not be the origin of the amide $B$ band. Similar arguments can be made with respect to the APRS structure, as follows. In order for two bands to participate in Fermi resonance with one another, their respective unperturbed frequencies, i.e., their frequencies before resonance takes place, must be close to one another and they must belong to the same symmetry species. The strong ir active $\mathrm{N}-\mathrm{H}$ stretching component in $\beta$ polypeptides has a transition moment that is essentially perpendicular to the chain axis. In the antiparallel chain sheet only the $B_{u}$ (rippled) or $B_{2}$ (pleated) species satisfy both of these conditions. Since the ${ }^{15} \mathrm{~N}$ isotope shifts ${ }^{25}$ of amide $\mathrm{B}\left(\Delta \nu=-23.9 \mathrm{~cm}^{-1}\right)$, amide $\mathrm{A}\left(\Delta \nu=-9.5 \mathrm{~cm}^{-1}\right)$, and amide II $(\Delta \nu=-14.4$ $\left.\mathrm{cm}^{-1}\right)$ in (Gly I $)_{n}$ are convincing evidence that the amide II mode is indeed the origin of amide $\mathrm{B}$, and since no overtone can have the correct symmetry, amide II bands of different symmetry species must combine to form the unperturbed amide $B$. The only possible combinations are

$$
\nu(0,0)_{\mathrm{II}}+\nu(\pi, 0)_{\mathrm{II}} \rightarrow \nu(\pi, 0)_{\mathrm{B}}
$$

or

$$
\nu(0, \pi)_{\mathrm{II}}+\nu(\pi, \pi)_{\mathrm{II}} \rightarrow \nu(\pi, 0)_{\mathrm{B}}
$$

Fermi resonance, which arises from the anharmonic terms in the potential energy function, causes the two frequencies that are relatively close to one another to share intensity, mix, and shift farther apart. If the two unperturbed frequencies are accidentally degenerate, the mixing will be complete and the subsequent shifts will be very large. In such a case the resulting two perturbed bands are almost equal mixtures of the components of the unperturbed vibrations, and are of equal intensity. Since amide A is at a higher frequency than amide $B$, the perturbed frequencies can be represented as: $:^{24,26}$

$$
\begin{aligned}
& \nu_{\mathrm{a}}=1 / 2\left(\left[\nu_{a}^{0}+\nu_{b}^{0}\right]+s\right) \\
& \nu_{\mathrm{b}}=1 / 2\left(\left[\nu_{a}^{0}+\nu_{b}^{0}\right]-s\right)
\end{aligned}
$$

where $\nu_{a}$ is the perturbed (observed) frequency of amide $\mathrm{A}, \nu_{b}$ is the perturbed amide $\mathrm{B}$ frequency, $\nu_{a}^{0}$ is the unperturbed $\mathrm{N}-\mathrm{H}$ stretching frequency, 
TABLE VIII

Fermi Resonance Calculations of Amide II $\nu(\pi, \pi)$ Frequencies (in $\mathrm{cm}^{-1}$ ) of $\beta$ Polypeptides

\begin{tabular}{|c|c|c|c|c|c|c|c|}
\hline & \multicolumn{3}{|c|}{ Observed } & \multicolumn{4}{|c|}{ Calculateda } \\
\hline & \multicolumn{2}{|c|}{ Frequency } & \multirow{2}{*}{$\begin{array}{c}\text { Intensity } \\
I_{R}\end{array}$} & \multirow[b]{2}{*}{$\nu_{a}{ }^{0}$} & \multirow[b]{2}{*}{$v_{b}{ }^{0}$} & \multirow{2}{*}{$\begin{array}{l}\nu\left(\delta, \delta^{\prime}\right) \\
{[\mathrm{FR}]^{\mathrm{b}}}\end{array}$} & \multirow{2}{*}{$\begin{array}{l}\nu\left(\delta, \delta^{\prime}\right) \\
{[T D C]^{c}}\end{array}$} \\
\hline & $\nu_{a}$ & $\nu_{b}$ & & & & & \\
\hline \multirow[t]{2}{*}{$(\text { Gly I })_{n}$} & 3300 & 3080 & 0.146 & 3272 & 3108 & 1591 & \multirow{2}{*}{$1588 \nu(\pi, \pi)$} \\
\hline & $3303^{d}$ & 3088 & 0.090 & 3268 & 3105 & 1588 & \\
\hline$(\text { Ala })_{n}$ & 3280 & 3072 & 0.223 & 3242 & 3109 & 1585 & $1587 \nu(\pi, \pi)$ \\
\hline$(\text { Ala-Gly })_{n}$ & 3284 & 3082 & 0.147 & 3258 & 3108 & 1573 & $1570 \nu(\pi, 0)$ \\
\hline$(\mathrm{Val})_{n}$ & 3270 & 3070 & 0.251 & 3230 & 3110 & 1574 & \\
\hline
\end{tabular}

a Based on Eq. (15). See Table VI for observed $\nu(0, \pi)$ frequencies.

b [FR] : from Fermi resonance.

c [TDC]: from transition dipole coupling (cf. Table VII).

d Ref. 24.

$\nu_{b}^{0}$ is the unperturbed amide II combination frequency, and $s$ is the observed splitting between amide $\mathrm{A}$ and amide $\mathrm{B}$.

The observed relative intensity of amide $B$ to amide $A$,

$$
I_{R}=\frac{I_{\mathrm{B}}}{I_{\mathrm{A}}}=\frac{s-\delta}{s+\delta}
$$

allows one to calculate $\delta$, the splitting in $\mathrm{cm}^{-1}$ between unperturbed bands, $\nu_{a}^{0}-\nu_{b}^{0}$. Using this approach for (Gly I $)_{n}$, Tsuboi obtained $\nu_{a}^{0}=3285, \nu_{b}^{0}$ $=3106$, and an amide II combination mode, $\nu(\pi, \pi)$ in our notation, with a frequency of $1588 \mathrm{~cm}^{-1}$.

We have performed intensity measurements on the amide $\mathrm{A}$ and amide B bands of (Gly I $)_{n},(\mathrm{Ala})_{n},(\text { Ala-Gly })_{n}$, and $(\mathrm{Val})_{n}$, and have calculated the values of the amide II $\nu(\pi, \pi)$ frequencies on the basis of Eq. (15). The results are given in Table VIII. We see that the Fermi resonance calculations give $\nu(\pi, \pi)$ frequencies of $\sim 1590$ and $1585 \mathrm{~cm}^{-1}$ for (Gly I) $n$ and (Ala) ${ }_{n}$, respectively. Recall (cf. Table VII) that the transition dipole coupling calculations predict frequencies of $1588 \mathrm{~cm}^{-1}$ and $1587 \mathrm{~cm}^{-1}$ for $(\mathrm{Gly} \mathrm{I})_{n}$ and (Ala $)_{n}$, respectively. The agreement between these independent calculations is remarkable.

It is, of course, possible that the combination of Eq. (14), viz. $\nu(0,0)$ and $\nu(\pi, 0)$, also contributes to the Fermi resonance. If we assume these modes in (Ala) ${ }_{n}$ to be the two Raman bands observed at 1538 and $1558 \mathrm{~cm}^{-1}$, then we would expect that $\nu_{b}^{0}=3096 \mathrm{~cm}^{-1}$. This correlates fairly well with the values predicted by transition dipole coupling, $\nu_{b}^{0}=3089 \mathrm{~cm}^{-1}$ (cf. Table VII), and by Fermi resonance calculations, $\nu_{b}^{0}=3109 \mathrm{~cm}^{-1}$. On the other hand, if the Raman band in (Gly I) $n$ that is observed at $1515 \mathrm{~cm}^{-1}$ is indeed the amide II $\nu(0,0)$ mode, then according to Eq. (14) the $\nu(\pi, 0)$ mode would have to occur in the vicinity of $1590 \mathrm{~cm}^{-1}$. Our calculations (cf. Table VII) place $\nu(\pi, 0)$ near $1563 \mathrm{~cm}^{-1}$, and therefore there is no reason to believe that the $\nu(0,0)+\nu(\pi, 0)$ combination contributes significantly in the case of (Gly I) $n$. 
In the $\alpha$-helix (manuscript in preparation) the unperturbed amide B has parallel dichroism and must be assigned to the totally symmetric mode. It must therefore be an overtone of an amide II fundamental. The fact that the fundamental is observed, and that the approach described here correctly predicts the unperturbed overtone frequency, enhances our confidence in the above analysis.

In many polypeptides an extremely weak band is present at approximately $2820 \mathrm{~cm}^{-1}$ in the $\alpha$-helix and at $2740-2800 \mathrm{~cm}^{-1}$ in the $\beta$ sheet. ${ }^{22}$ The low-temperature behavior of this band has been observed to parallel the behavior of the amide II modes, and this band disappears in N-deuterated species. In the $\alpha$-helix this band has parallel, and in the $\beta$ sheet perpendicular, dichroism. We therefore believe that this band has its origin in a combination $\mathrm{N}-\mathrm{H}$ in-plane bending mode. The only available combinations are again $\nu(0,0)+\nu(\pi, 0) \rightarrow \nu(\pi, 0)$ and $\nu(0, \pi)+\nu(\pi, \pi) \rightarrow \nu(\pi, 0)$. In both cases the resulting band would have $B_{u}$ or $B_{2}$ symmetry in the rippled or pleated sheets, respectively. In (Gly $\mathrm{I})_{n}$ this band is observed as a weak broad absorption from $2750-2800 \mathrm{~cm}^{-1}$. Therefore, the observed $1515 \mathrm{~cm}^{-1}$ amide II and the observed $1236 \mathrm{~cm}^{-1}$ amide III bands, and/or the observed amide III $\nu(0, \pi)$ mode at $1214 \mathrm{~cm}^{-1}$ and the calculated amide II $\nu(\pi, \pi)$ mode at $1585 \mathrm{~cm}^{-1}$, are likely combinations. Fermi resonance in $\mathrm{N}$-deuterated polypeptides also gives rise to observed bands at 2464 and $2416 \mathrm{~cm}^{-1}$ that are probably due to a combination band, amide $\mathrm{II}^{\prime}$ plus amide III', in resonance with $\mathrm{N}-\mathrm{D}$ stretching. Fermi resonance arises from anharmonic potential energy terms, the intensity of the combination or overtone band being related to the amount of anharmonicity in the corresponding fundamentals. Therefore, the known anharmonicity in the $\mathrm{N}-\mathrm{H}$ in-plane bending mode explains both the presence of amide $\mathrm{B}$ (and of amide $\left.\mathrm{B}^{\prime}\right)$ and the absorption from $2750-2800 \mathrm{~cm}^{-1}$.

An important result of the foregoing analysis is that, as can be seen from Table VIII, $\nu_{a}^{0}$, the unperturbed N-H stretching frequency, is considerably higher for (Gly I $)_{n}$ than for the other polypeptides. The relative unperturbed $\mathrm{N}-\mathrm{H}$ stretching frequency should be indicative of the relative strength of the respective hydrogen bond. As we have previously stated, the $\mathrm{N}-\mathrm{H}$...O geometry in the APRS structure is nonlinear, resulting in an expected weaker $\mathrm{H}$... O bond than in the APPS structure. The fact that the unperturbed $\mathrm{N}-\mathrm{H}$ stretching frequency is found to be so much higher in $(\text { Gly } I)_{n}$ provides additional evidence that this polypeptide assumes the rippled-sheet structure.

Amide $V$ Mode. The amide $\mathrm{V}$ mode, due to $\mathrm{C}-\mathrm{N}$ torsion and $\mathrm{N}-\mathrm{H}$ outof-plane bending, is, in most $\beta$ polypeptides, a very broad band centered at approximately $700 \mathrm{~cm}^{-1}$ whose wings extend down as far as $400 \mathrm{~cm}^{-1}$. In (Gly I) $)_{n}$ the band is less broad. Krimm and Kuroiwa ${ }^{27}$ observed amide $\mathrm{V}$ at $708 \mathrm{~cm}^{-1}$ at room temperature and at $720 \mathrm{~cm}^{-1}$ at $-170^{\circ} \mathrm{C}$. Therefore, we can assume that this vibration is highly influenced by lattice modes. Normal vibration calculations confirm this dependence of amide $\mathrm{V}$ on the intermolecular force field. 
TABLE IX

Observed Amide $V$ and Amide $V^{\prime}$ Frequencies (in $\mathrm{cm}^{-1}$ ) for $\beta$ Polypeptides and $\alpha$-Nylons

\begin{tabular}{|c|c|c|c|}
\hline & Amide V & Amide $V^{\prime}$ & $\Delta \nu$ \\
\hline Poly(L-alanine $)^{a}$ & 703 & 520 & 183 \\
\hline Poly(L-valine) & 710 & 531 & 178 \\
\hline Poly $(D L-\alpha \text {-amino- } n \text {-butyric acid })^{b}$ & 703 & 531 & 172 \\
\hline Poly(DL-norleucine $)^{b}$ & 705 & 536 & 169 \\
\hline Poly(DL-norvaline $)^{b}$ & 704 & 534 & 170 \\
\hline $\operatorname{Poly}(\gamma \text {-methyl-L-glutamate })^{a}$ & 700 & 531 & 169 \\
\hline Polyglycine $I^{c}$ & 708 & 504 & 204 \\
\hline Nylon-4 d & 692 & 495 & 197 \\
\hline Nylon-6 & 692 & 496 & 196 \\
\hline Nylon-8d & 688 & 494 & 194 \\
\hline
\end{tabular}

a Masuda, Y., Kukushima, K., Fujii, T. \& Miyazawa, T. (1969) Biopolymers 8, $91-99$.

b Ref. 29 .

c Ref. 3 .

d Ref. 1 .

In the nylons and in all $\beta$ polypeptides there is relatively little difference in the observed frequencies of the amide $V$ vibrations (see table IX). However, the shift of amide $\mathrm{V}$ on $\mathrm{N}$-deuteration for the $\beta$ polypeptides is approximately $170 \mathrm{~cm}^{-1}$, whereas for the even nylons this shift is $\Delta \nu \cong 200$ $\mathrm{cm}^{-1}$. For $(\mathrm{Gly} \mathrm{I})_{n}$ this shift is $204 \mathrm{~cm}^{-1}$, which seems to indicate that (Gly I) $n$ is better characterized as nylon-2 than as a $\beta$ polypeptide. It is interesting to note that the APRS structure proposed for (Gly I) $n$ is more similar to that of the even nylons than it is to that of the other $\beta$ polypeptides. ${ }^{10}$

Low-Frequency Region. A broad ir band at approximately $140 \mathrm{~cm}^{-1}$ was observed in the spectrum of (Gly I $)_{n}$ by Krimm and Kuroiwa. ${ }^{28}$ Moreover, in the spectra of several other polypeptides in the $\beta$ form Itoh et al. ${ }^{29}$ have observed low-frequency ir bands between $110 \mathrm{~cm}^{-1}$ and 130 $\mathrm{cm}^{-1}$. These have all been assigned to a translational lattice vibration belonging to the $B_{3}$ symmetry species. Fanconi ${ }^{30}$ investigated this spectral region, and an ir band observed by him at $133 \mathrm{~cm}^{-1}$ for (Gly I) $n$ (and at 122 $\mathrm{cm}^{-1}$ for (Ala $)_{n}$ ) was used to determine the magnitude of the $f(\mathrm{H} \ldots \mathrm{O})$ force constant $(0.15 \mathrm{mdyn} / \AA)$. The results obtained by using this force constant to calculate this translatory normal mode in (Ala) $)_{n}$, poly (L- $\alpha$-amino- $n$ butyric acid), and $(\mathrm{Val})_{n}$ led him to postulate that for APPS homopolypeptides the $B_{3}$ translatory lattice frequency varies inversely with the square of the mass of the repeat unit. These calculations, which assumed a simplified mass model of the APPS lattice, predicted the $\mathrm{H}$... O stretching mode at $133 \mathrm{~cm}^{-1}$ for (Gly I) $)_{n}$, at $119 \mathrm{~cm}^{-1}$ for (Ala) $)_{n}$, and at $100 \mathrm{~cm}^{-1}$ for $(\mathrm{Val})_{n}$.

We have done calculations on these same polypeptides, with all atoms and optimized sheet-structural parameters included. Our results contradict Fanconi's conclusion. Using $f(\mathrm{H} \ldots \mathrm{O})=0.15$, the value adjusted 
TABLE X

Low-Frequency Region of Polyglycine I

\begin{tabular}{cccc}
\hline \multicolumn{2}{c}{ Observed Frequencies } & \multicolumn{2}{c}{ Calculated Frequencies } \\
Raman & Infrared & Pleated & Rippled \\
\hline $170(175) w^{\mathrm{b}}$ & & $?$ & $178 \mathrm{~A}_{g}$ \\
$112(114) w$ & 140 & $133 B_{3}$ & $128 \mathrm{~B}_{u}$ \\
& & $106 B_{3}$ & $102 B_{g}$ \\
$82(87) s$ & $75 B_{1}$ & $80 A_{g}$ \\
\hline
\end{tabular}

a Using force fields of Ref. 3 , and $f(\mathrm{H} \cdots O)=0.15 \mathrm{mdyn} / \AA$.

b Frequencies in parentheses observed at $120^{\circ} \mathrm{K}$ (J. F. Rabolt \& S. Krimm, private communication).

by Fanconi to predict his observed $133 \mathrm{~cm}^{-1}$ band in (Gly I) ${ }_{n}$, our calculations predict the $B_{3}$ lattice translation at $133 \mathrm{~cm}^{-1}$ in $(\mathrm{Gly} \mathrm{I})_{n}$ and at 134 $\mathrm{cm}^{-1}$ in $(\mathrm{Val})_{n}$. In (Ala $)_{n}$ the stretching of the intermolecular hydrogen bond is found to contribute significantly to normal modes of $B_{3}$ symmetry at $159 \mathrm{~cm}^{-1}$ and also at $90 \mathrm{~cm}^{-1}$.

In addition to the aforementioned far ir absorption at $140 \mathrm{~cm}^{-1}$, the (Gly I) ${ }_{n}$ spectrum has three temperature-sensitive low-frequency Raman bands at $170 \mathrm{~cm}^{-1}, 112 \mathrm{~cm}^{-1}$, and $82 \mathrm{~cm}^{-1}$ that shift to $175 \mathrm{~cm}^{-1}, 114 \mathrm{~cm}^{-1}$, and $87 \mathrm{~cm}^{-1}$ at $120^{\circ} \mathrm{K}$ (J. F. Rabolt \& S. Krimm, private communication). The direction of the shifts suggests that there are lattice contributions to all of these frequencies. The far ir band shifts upward by $8 \mathrm{~cm}^{-1}$ at liquid nitrogen temperatures.

In our normal vibration calculations for both the pleated-and rippledsheet structures of $(\mathrm{Gly} \mathrm{I})_{n}$ using $f(\mathrm{H} \ldots \mathrm{O})=0.15$ (see Table X), the only normal mode of the pleated sheet near $140 \mathrm{~cm}^{-1}$ with some lattice involvement is the $B_{3}(\mathrm{H} \ldots \mathrm{O})$ translatory mode. Although Fukushima et al., ${ }^{31}$ reported that intramolecular normal modes of $B_{3}$ symmetry in the APPS structure associated with predominately in-plane motions of the peptide group should be weak in the ir, it is still possible that lattice translatory modes, such as the $B_{3} \mathrm{H}$...O stretching mode, may not be weak. Other arguments, however, do not favor such an assignment. For example, in (Gly I) $n$ strong Raman bands are generally assigned to calculated frequencies that are associated with the totally symmetric ( $A_{g}$ in rippled, $A$ in pleated) symmetry species. However, for the pleated-sheet structure the strong Raman band observed at $82 \mathrm{~cm}^{-1}$ would probably have to be associated with a rotatory lattice vibration of $B_{1}$ symmetry, calculated at $75 \mathrm{~cm}^{-1}$. Such an assignment in (Gly I) ${ }_{n}$ would be the only assignment of a strong Raman band to a normal mode of $B_{1}$ symmetry. In the rippled sheet the far ir band at $140 \mathrm{~cm}^{-1}$ can be assigned to a $B_{u}$ mode calculated with the refined force field at $145 \mathrm{~cm}^{-1}$. Although this is not a lattice vibration, it is influenced to a large degree by $\mathrm{H}$... O stretching ( $49 \%$ of the potential energy). The strong Raman band at $87 \mathrm{~cm}^{-1}$ (low temperature) can be assigned to a lattice mode that is calculated at $96 \mathrm{~cm}^{-1}$ and has $A_{g}$ symmetry. 
TABLE XI

Force Constants for Polyglycine I

\begin{tabular}{|c|c|}
\hline Force Constant & Value \\
\hline 1. $f\left(\mathrm{~N}-\mathrm{C}^{\alpha}\right)$ & 5.043 \\
\hline 2. $f\left(\mathrm{C}^{\alpha}-\mathrm{C}\right)$ & 4.509 \\
\hline 3. $f(\mathrm{C}-\mathrm{N})$ & 6.299 \\
\hline 4. $f(\mathrm{C}=0)$ & 9.720 \\
\hline 5. $f(\mathrm{~N}-\mathrm{H})$ & 5.840 \\
\hline 6. $f\left(\mathrm{C}^{\alpha}-\mathrm{H}\right)$ & 4.564 \\
\hline 7. $f\left(\mathrm{CNC}^{\alpha}\right)$ & 0.787 \\
\hline 8. $f\left(\mathrm{NC}^{\alpha} \mathrm{C}\right)$ & $0.819(0.032)^{\mathrm{a}}$ \\
\hline 9. $f\left(\mathrm{C}^{\alpha} \mathrm{CN}\right)$ & 1.400 \\
\hline 10. $f\left(\mathrm{C}^{\alpha} \mathrm{C}=\mathrm{O}\right)$ & 1.246 \\
\hline 11. $f(\mathrm{NC}=\mathrm{O})$ & \\
\hline $\begin{array}{l}\text { 12. } f(\mathrm{CNH}) \\
\text { 13. } f\left(\mathrm{C}^{\alpha} \mathrm{NH}\right)\end{array}$ & $0.527(0.015)$ \\
\hline 14. $f\left(\mathrm{NC}^{\alpha} \mathrm{H}\right)$ & 0.715 \\
\hline 15. $f\left(\mathrm{CC}^{\alpha} \mathrm{H}\right)$ & 0.684 \\
\hline 16. $f\left(\mathrm{HC}^{\alpha} \mathrm{H}\right)$ & $0.584(0.013)$ \\
\hline 17. $f(C=0$ op $)$ & $0.587(0.019)$ \\
\hline 18. $f(\mathrm{~N}-\mathrm{H}$ op $)$ & $0.129(0.006)$ \\
\hline 19. $f\left(\mathrm{~N}-\mathrm{C}^{\alpha}\right.$ tor $)$ & 0.037 \\
\hline 20. $f\left(\mathrm{C}^{\alpha}-\mathrm{C}\right.$ tor $)$ & 0.037 \\
\hline 21. $f(\mathrm{C}-\mathrm{N}$ tor $)$ & $0.680(0.014)$ \\
\hline 22. $f\left(\mathrm{~N}-\mathrm{C}^{\alpha}, \mathrm{C}^{\alpha}-\mathrm{C}\right)$ & 0.300 \\
\hline 23. $f\left(\mathrm{C}^{\alpha}-\mathrm{C}, \mathrm{C}-\mathrm{N}\right)$ & 0.300 \\
\hline 24. $f\left(\mathrm{C}-\mathrm{N}, \mathrm{N}-\mathrm{C}^{\alpha}\right)$ & 0.300 \\
\hline 25. $f\left(\mathrm{C}^{\alpha}-\mathrm{C}, \mathrm{C}=\mathrm{O}\right)$ & 0.500 \\
\hline 26. $f(\mathrm{C}-\mathrm{N}, \mathrm{C}=-\mathrm{O})$ & 0.500 \\
\hline 27. $f\left(\mathrm{C}-\mathrm{N}, \mathrm{CNC}^{\alpha}\right)$ & 0.300 \\
\hline 28. $f\left(\mathrm{~N}-\mathrm{C}^{\alpha}, \mathrm{CNC}^{\alpha}\right)$ & 0.300 \\
\hline 29. $f\left(N-C^{\alpha}, N^{\alpha} C^{2}\right)$ & 0.300 \\
\hline 30. $f\left(\mathrm{C}^{\alpha}-\mathrm{C}, \mathrm{NC}^{\alpha} \mathrm{C}\right)$ & 0.300 \\
\hline 31. $f\left(\mathrm{C}^{\alpha}-\mathrm{C}, \mathrm{C}^{\alpha} \mathrm{CN}\right)$ & 0.300 \\
\hline 32. $f\left(\mathrm{C}-\mathrm{N}, \mathrm{C}^{\alpha} \mathrm{CN}\right)$ & 0.300 \\
\hline 33. $f\left(\mathrm{C}^{\alpha}-\mathrm{C}, \mathrm{C}^{\alpha} \mathrm{C}=\mathrm{O}\right)$ & 0.200 \\
\hline 34. $f(\mathrm{C}-\mathrm{N}, \mathrm{NC}=\mathrm{O})$ & 0.200 \\
\hline 35. $f\left(\mathrm{C}=\mathrm{O}, \mathrm{C}^{\alpha} \mathrm{C}=\mathrm{O}\right)$ & 0.450 \\
\hline 36. $f(\mathrm{C}=\mathrm{O}, \mathrm{NC}=\mathrm{O})$ & 0.450 \\
\hline $\left.\begin{array}{l}\text { 37. } f(\mathrm{C}-\mathrm{N}, \mathrm{CNH}) \\
\text { 38. } f\left(\mathrm{~N}-\mathrm{C}^{\alpha}, \mathrm{C}^{\alpha} \mathrm{NH}\right)\end{array}\right\}$ & 0.294 \\
\hline 39. $f\left(\mathrm{~N}-\mathrm{C}^{\alpha}, \mathrm{NC}^{\alpha} \mathrm{H}\right)$ & 0.517 \\
\hline 40. $f\left(\mathrm{~N}-\mathrm{C}^{\alpha}, \mathrm{CC}^{\alpha} \mathrm{H}\right)$ & 0.026 \\
\hline $\begin{array}{l}\text { 41. } f\left(\mathrm{C}^{\alpha}-\mathrm{C}, \mathrm{NC}^{\alpha} \mathrm{H}\right) \\
42 . f\left(\mathrm{C}^{\alpha}-\mathrm{C}, \mathrm{CC}^{\alpha} \mathrm{H}\right)\end{array}$ & 0.205 \\
\hline 43. $f\left(\mathrm{CNC}^{\alpha}, \mathrm{NC}^{\alpha} \mathrm{C}\right)$ & 0.000 \\
\hline 44. $f\left(\mathrm{NC}^{\alpha} \mathrm{C}, \mathrm{C}^{\alpha} \mathrm{CN}\right)$ & 0.000 \\
\hline 45. $f\left(\mathrm{C}^{\alpha} \mathrm{CN}, \mathrm{CNC}^{\alpha}\right)$ & 0.000 \\
\hline 46. $f\left(\mathrm{NC}^{\alpha} \mathrm{C}, \mathrm{C}^{\alpha} \mathrm{C}=\mathrm{O}\right)$ & 0.000 \\
\hline 47. $f\left(\mathrm{CNC}^{\alpha}, \mathrm{NC}=\mathrm{O}\right)$ & 0.000 \\
\hline 48. $f\left(\mathrm{C}^{\alpha} \mathrm{CN}, \mathrm{CNH}\right)$ & 0.200 \\
\hline 49. $f\left(\mathrm{NC}^{\alpha} \mathrm{C}, \mathrm{C}^{\alpha} \mathrm{NH}\right)$ & -0.100 \\
\hline
\end{tabular}


TABLE XI (continued)

\begin{tabular}{|c|c|}
\hline Force Constant & Value \\
\hline 50. $f\left(\mathrm{CNC}^{\alpha}, \mathrm{NC}^{\alpha} \mathrm{H}\right)$ & 0.000 \\
\hline 51. $f\left(\mathrm{CNC}^{\alpha}, \mathrm{NC}^{\alpha} \mathrm{H}^{\prime}\right)$ & 0.000 \\
\hline 52. $f\left(\mathrm{C}^{\alpha} \mathrm{CN}, \mathrm{CC}^{\alpha} \mathrm{H}\right)$ & 0.000 \\
\hline 53. $f\left(\mathrm{C}^{\alpha} \mathrm{CN}, \mathrm{CC}^{\alpha} \mathrm{H}^{\prime}\right)$ & 0.000 \\
\hline 54. $f\left(\mathrm{NC}^{\alpha} \mathrm{H}, \mathrm{NC}^{\alpha} \mathrm{H}^{\prime}\right)$ & 0.026 \\
\hline 55. $f\left(\mathrm{CCH}, \mathrm{CCH}^{\prime}\right)$ & -0.023 \\
\hline 56. $f\left(\mathrm{NC}^{\alpha} \mathrm{H}, \mathrm{CC}^{\alpha} \mathrm{H}\right)$ & 0.033 \\
\hline 57. $f\left(\mathrm{NC}^{\alpha} \mathrm{H}, \mathrm{HC}^{\alpha} \mathrm{H}\right)$ & 0.0767 \\
\hline 58. $f\left(\mathrm{CC}^{\alpha} \mathrm{H}, \mathrm{HC}^{\alpha} \mathrm{H}\right)$ & 0.0215 \\
\hline 59. $f(\mathrm{NC}=\mathrm{O}, \mathrm{CNH})$ & 0.251 \\
\hline 60. $f\left(\mathrm{C}^{\alpha} \mathrm{C}=\mathrm{O}, \mathrm{CC}^{\alpha} \mathrm{H}\right)$ & 0.100 \\
\hline 61. $f\left(\mathrm{C}^{\alpha} \mathrm{C}=\mathrm{O}, \mathrm{CC}^{\alpha} \mathrm{H}^{\prime}\right)$ & 0.000 \\
\hline 62. $f\left(\mathrm{C}^{\alpha} \mathrm{NH}, \mathrm{NC}^{\alpha} \mathrm{H}\right)$ & 0.058 \\
\hline 63. $f\left(\mathrm{C}^{\alpha} \mathrm{NH}, \mathrm{NC}^{\alpha} \mathrm{H}^{\prime}\right)$ & 0.077 \\
\hline 64. $f\left(\mathrm{C}=\mathrm{O}\right.$ op, $\left.\mathrm{NC}^{\alpha} \mathrm{C}\right)$ & $0.020(0.015)$ \\
\hline 65. $f(\mathrm{C}=\mathrm{O}$ op, $\mathrm{CCH})$ & 0.100 \\
\hline 66. $f\left(\mathrm{C}=\mathrm{O}\right.$ op, $\left.\mathrm{CCH}^{\prime}\right)$ & 0.000 \\
\hline 67. $f\left(\mathrm{~N}-\mathrm{H}\right.$ op, $\left.\mathrm{NC}^{\alpha} \mathrm{C}\right)$ & 0.000 \\
\hline 68. $f\left(\mathrm{~N}-\mathrm{H}\right.$ op, $\left.\mathrm{NC}^{\alpha} \mathrm{H}\right)$ & 0.000 \\
\hline 69. $f\left(\mathrm{~N}-\mathrm{H}\right.$ op, $\left.\mathrm{NC}^{\alpha} \mathrm{H}^{\prime}\right)$ & 0.100 \\
\hline 70. $f(\mathrm{C}=\mathrm{O}$ op, $\mathrm{N}-\mathrm{H}$ op $)$ & $0.114(0.009)$ \\
\hline 71. $f(\mathrm{C}=\mathrm{O}$ op, $\mathrm{C}-\mathrm{N}$ tor $)$ & $0.111(0.02)$ \\
\hline 72. $f(\mathrm{~N}-\mathrm{H}$ op, $\mathrm{C}-\mathrm{N}$ tor $)$ & -0.130 \\
\hline 73. $f(\mathrm{H} \cdot \mathrm{O})$ & 0.125 \\
\hline 74. $f(\mathrm{C}=\mathrm{O} \cdots \mathrm{H} \mathrm{ip})$ & 0.010 \\
\hline $75 . f_{\tau}(\mathrm{C}=\mathrm{O})$ & 0.001 \\
\hline 76. $f(\mathrm{~N}-\mathrm{H} \cdots \mathrm{O}$ ip $)$ & 0.030 \\
\hline 77. $f_{\tau}(\mathrm{N}-\mathrm{H})$ & 0.0015 \\
\hline 78. $f\left(\mathrm{H}^{\alpha} \cdots \mathrm{H}^{\alpha}\right)$ & 0.007 \\
\hline 79. $F_{10} \mathrm{I}$ & 0.102 \\
\hline $80 . F_{01} \mathrm{I}$ & -0.244 \\
\hline 81. $F_{11}^{01} \mathrm{I}$ & 0.160 \\
\hline $82 . F_{10} \mathrm{II}$ & -0.036 \\
\hline $83 . F_{01}$ II & -0.0095 \\
\hline 84. $F_{11}$ Il & 0.0091 \\
\hline
\end{tabular}

a Figure in parenthesis is dispersion for force constants that were allowed to refine.

An observed ir band at $122 \mathrm{~cm}^{-1}$ in (Ala) ${ }_{n},{ }^{30}$ which was thought to be $\mathrm{H}$... O stretching, has recently been observed at liquid nitrogen temperature. ${ }^{32}$ This band does not have the large temperature shift and change in band shape associated with a lattice mode. Our calculations show that this band can be assigned to a skeletal deformation mode of $B_{2}$ symmetry. The strong low-frequency Raman bands in (Ala $)_{n}$ can also be assigned to totally symmetric A modes.

The assumption of a rippled-sheet structure for $(\mathrm{Gly} \mathrm{I})_{n}$, therefore, makes it possible to explain consistently the far ir and low-frequency Raman spectra of both polypeptides. 
TABLE XII

Observed and Calculated Frequencies (in $\mathrm{cm}^{-1}$ ) of Crystalline Polyglycine I

\begin{tabular}{|c|c|c|c|c|c|c|}
\hline \multicolumn{2}{|c|}{$\begin{array}{l}\text { Observed } \\
\text { Frequencies }\end{array}$} & \multirow[b]{2}{*}{$A_{g}$} & \multicolumn{2}{|c|}{$\begin{array}{l}\text { Calculated } \\
\text { Frequencies }\end{array}$} & \multirow[b]{2}{*}{$B_{u}$} & \multirow{2}{*}{ Potential Energy Distributiona } \\
\hline Raman & Infrared & & $A_{u}$ & $B_{g}$ & & \\
\hline & $3272^{\mathrm{b}}$ & 3272 & 3272 & 3272 & 3272 & NH str $(98)$ \\
\hline 2932 & 2929 & 2933 & 2931 & 2932 & 2932 & $\mathrm{C}^{\alpha} \mathrm{H}$ asym $\operatorname{str}(99)$ \\
\hline \multirow[t]{3}{*}{2869} & 2869 & 2860 & 2860 & 2860 & 2860 & $\mathrm{C}^{\alpha} \mathrm{H}$ sym str $(99)$ \\
\hline & & & & 1690 & & $\mathrm{C}=\mathrm{O} \operatorname{str}(77), \mathrm{CN} \operatorname{str}(14), \mathrm{C} \alpha \mathrm{CN}$ def (12) \\
\hline & 1685 & & 1685 & & & $\mathrm{C}=\mathrm{O}$ str $(76), \mathrm{CN} \operatorname{str}(16), \mathrm{C}^{\alpha} \mathrm{CN}$ def (12) \\
\hline \multirow[t]{6}{*}{1674} & & 1674 & & & & $\mathrm{C}=\mathrm{O} \operatorname{str}(76), \mathrm{CN} \operatorname{str}(16), \mathrm{C}^{\alpha} \mathrm{CH}$ def (12) \\
\hline & 1636 & & & & 1637 & $\mathrm{C}=\mathrm{O} \operatorname{str}(77), \mathrm{CN} \operatorname{str}(16), \mathrm{C}^{\alpha} \mathrm{CN}$ def (12) \\
\hline & & & & 1588 & & \\
\hline & & & & & 1563 & $\begin{array}{l}\mathrm{NH} \mathrm{ipb}(42), \mathrm{CN} \operatorname{str}(26), \mathrm{C}^{\alpha} \mathrm{C} \operatorname{str}(18), \\
\mathrm{NC}^{\alpha} \operatorname{str}(11), \mathrm{C}=\mathrm{O} \mathrm{ipb}(11)\end{array}$ \\
\hline & 1517 & & 1516 & & & \\
\hline & & 1515 & & & & $\begin{array}{l}\text { NH ipb (43), CN } \operatorname{str}(31), C=O \text { opb (13) } \\
\quad \mathrm{C}^{\alpha} \mathrm{C} \operatorname{str}(12)\end{array}$ \\
\hline \multirow[t]{4}{*}{1460} & & 1460 & & & & $\mathrm{CH}_{2}$ bend $(97)$ \\
\hline & & & 1460 & & & $\mathrm{CH}_{2}$ bend $(97)$ \\
\hline & & & & 1432 & & $\mathrm{CH}_{2}$ bend $(98)$ \\
\hline & 1432 & & & & 1432 & $\mathrm{CH}_{2}$ bend $(99)$ \\
\hline \multirow[t]{2}{*}{1410} & & 1393 & & & & \\
\hline & 1408 & & 1391 & & & $\mathrm{CH}_{2}$ wag(60), $\mathrm{NH} \operatorname{jpb}(19), \mathrm{C}^{\alpha} \mathrm{C} \operatorname{str}(17)$ \\
\hline \multirow[t]{2}{*}{1341} & 1400 & & & 1350 & & \\
\hline & 1338 & & & & 1353 & $\mathrm{CH}_{2} \operatorname{wag}(75)$ \\
\hline \multirow[t]{4}{*}{1255} & & $125^{2} 2$ & & & & \\
\hline & & & 1252 & & & $\mathrm{CH}_{2}$ twist $(79)$ \\
\hline & & & & 1300 & & $\begin{array}{l}\mathrm{NH} \text { ipb(41), } \mathrm{CH}_{2} \text { twist }(14) \\
\quad \mathrm{C}^{\alpha} \mathrm{C} \operatorname{str}(13), \mathrm{C}=\mathrm{O} \text { ipb (12) }\end{array}$ \\
\hline & 1295 & & & & 1286 & $\begin{array}{l}\mathrm{NH} \text { ipb(43), } \mathrm{C}^{\alpha} \mathrm{C} \operatorname{str}(13), \mathrm{C}=\mathrm{O} \text { ipb (12), } \\
\mathrm{CH}_{2} \text { twist (11) }\end{array}$ \\
\hline \multirow[t]{2}{*}{1234} & & & & 1250 & & $\mathrm{CH}_{2}$ twist $(76), \mathrm{NH}$ ipb (12) \\
\hline & 1236 & & & & 1245 & $\mathrm{CH}_{2}$ twist (79) \\
\hline \multirow[t]{2}{*}{1220} & & 1220 & & & & \\
\hline & 1214 & & 1219 & & & $\begin{array}{l}\mathrm{NH} \text { ipb (28), } \mathrm{CH}_{2} \text { wag (29), } \mathrm{CN} \text { str (16), } \\
\mathrm{NC}^{\alpha} \text { str (14), } \mathrm{CH}_{2} \text { twist (13) }\end{array}$ \\
\hline \multirow[t]{3}{*}{1162} & & 1159 & & & & $\mathrm{NC}^{\alpha} \operatorname{str}(62), \mathrm{C}^{\alpha} \mathrm{C} \operatorname{str}(14)$ \\
\hline & & & 1158 & & & \\
\hline & 1054 & & & & & \\
\hline \multirow[t]{3}{*}{1034} & & & & & & PGII impurity (?) \\
\hline & 1016 & & & & 1024 & \\
\hline & & & & & & $\mathrm{NC}^{\alpha} \operatorname{str}(67), \mathrm{C}^{\alpha} \mathrm{C} \operatorname{str}(11)$ \\
\hline \multirow[t]{7}{*}{1021} & & & & 1020 & & \\
\hline & & 1001 & & & & $\mathrm{CH}_{2} \operatorname{rock}(51), \mathrm{C}=\mathrm{O} \operatorname{str}(10)$ \\
\hline & & & 998 & & & $\mathrm{CH}_{2} \operatorname{rock}(56)$ \\
\hline & & & & 973 & & $\mathrm{CH}_{2}$ rock $(70)$ \\
\hline & 987 & & & & 992 & $\mathrm{CH}_{2}$ rock $(59), \mathrm{CN}$ str $(11)$ \\
\hline & & 944 & & & & $\begin{array}{l}\mathrm{CH}_{2} \text { rock }(24), \mathrm{CN} \operatorname{str}(13), \mathrm{C}^{\alpha} \mathrm{C} \text { str }(12), \\
\mathrm{C}=\mathrm{O} \text { str }(10), \mathrm{NC}^{\alpha} \mathrm{C} \text { def }(10)\end{array}$ \\
\hline & 936 & & 941 & & & $\begin{array}{l}\mathrm{CH}_{2} \text { rock }(18), \mathrm{CN} \operatorname{str}(15), \mathrm{C}^{\alpha} \mathrm{C} \text { str }(12), \\
\mathrm{C}=\mathrm{O} \operatorname{str}(12), \mathrm{NC}^{\alpha} \mathrm{C} \text { def (11) }\end{array}$ \\
\hline \multirow[t]{8}{*}{884} & & & & 887 & & $\mathrm{C}^{\alpha} \mathrm{C} \operatorname{str}(27), \mathrm{CN} \operatorname{str}(27), \mathrm{C}=\mathrm{O}$ str (14) \\
\hline & $888 ?$ & & & & 893 & $\mathrm{C}^{\alpha} \mathrm{C} \operatorname{str}(27), \mathrm{CN} \operatorname{str}(26), \mathrm{C}=\mathrm{O} \operatorname{str}(14)$ \\
\hline & & & & 759 & & \\
\hline & & & & & 760 & 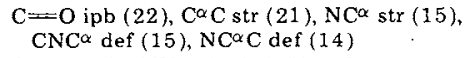 \\
\hline & & & 730 & & & $\begin{array}{l}\text { CN tor(73), NH opb (35), H } \cdots(17) \\
\text { NH. O Ipb }(14)\end{array}$ \\
\hline & & 722 & & & & $\begin{array}{l}\mathrm{CN} \text { tor }(71), \mathrm{NH} \text { opb }(37), \mathrm{NH} \cdots \mathrm{O} \text { ipb } \\
(15), \mathrm{H} \cdots \mathrm{O}(14)\end{array}$ \\
\hline & & & & 724 & & $\begin{array}{l}\mathrm{CN} \text { tor }(66), \mathrm{NH} \text { opb }(21), \mathrm{H} \cdots \mathrm{O}(15), \\
\mathrm{CH}_{2} \operatorname{rock}(14), \mathrm{NH} \cdots \mathrm{O} \text { ipb (12) }\end{array}$ \\
\hline & $708(720)$ & & & & 716 & $\begin{array}{l}\text { CN tor }(75), \mathrm{NH}_{\text {opb }}(24), \mathrm{H} \cdots \mathrm{O}(13) \\
\mathrm{NH} \cdot \mathrm{O} \text { ipb (13) }\end{array}$ \\
\hline
\end{tabular}


TABLE XII (continued)

\begin{tabular}{|c|c|c|c|c|c|c|}
\hline \multicolumn{2}{|c|}{$\begin{array}{c}\text { Observed } \\
\text { Frequencies }\end{array}$} & \multicolumn{4}{|c|}{$\begin{array}{l}\text { Calculated } \\
\text { Frequencies }\end{array}$} & \multirow[b]{2}{*}{ Potential Energy Distribution } \\
\hline Raman & Infrared & $A_{g}$ & $A_{u}$ & $B_{g}$ & $B_{u}$ & \\
\hline & 628 & & 629 & & & $\begin{array}{l}\mathrm{C}=\mathrm{O} \mathrm{ipb}(35), \mathrm{C}=\mathrm{O} \mathrm{opb}(25), \mathrm{CH}_{2} \\
\text { rock (11) }\end{array}$ \\
\hline & & 628 & & & & $\begin{array}{l}\mathrm{C}=\mathrm{O} \mathrm{ipb} \mathrm{(37),} \mathrm{C}=\mathrm{O} \text { opb }(22), \mathrm{CH}_{2} \\
\text { rock (11) }\end{array}$ \\
\hline & 614 & & & & 618 & $\begin{array}{l}\mathrm{C}=\mathrm{O} \text { opb (52), } \mathrm{C}^{\alpha} \mathrm{CN} \operatorname{def}(18), \mathrm{NH} \text { opb } \\
\text { (14), } \mathrm{CH}_{2} \text { wag }(10)\end{array}$ \\
\hline & & & & 627 & & $\mathrm{C}=\mathrm{O}$ opb $(67), \mathrm{NH}$ opb (19) \\
\hline \multirow[t]{3}{*}{599} & & & & 589 & & $\mathrm{C}^{\alpha} \mathrm{CN}$ def $(58)$ \\
\hline & & & & & 585 & $\mathrm{C}^{\alpha} \mathrm{CN}$ def $(45), \mathrm{C}=\mathrm{O}$ opb (18) \\
\hline & 589 & & 585 & & & $\begin{array}{l}\mathrm{C}=\mathrm{O} \text { opb }(39), \mathrm{C}=\mathrm{O} \text { ipb }(30), \mathrm{C}^{\alpha} \mathrm{C} \\
\operatorname{str}(12)\end{array}$ \\
\hline 589 & & 584 & & & & $\begin{array}{l}\mathrm{C}=\mathrm{O} \text { opb }(40), \mathrm{C}=\mathrm{O} \text { ipb }(28), \mathrm{C}^{\alpha} \mathrm{C} \\
\operatorname{str}(12)\end{array}$ \\
\hline \multirow[t]{4}{*}{327} & & & & 318 & & $\begin{array}{l}\mathrm{NC}^{\alpha} \mathrm{C} \text { def }(25), \mathrm{NH} \text { opb (23), C=O } \\
\mathrm{ipb}(17)\end{array}$ \\
\hline & 321 & & & & 317 & $\begin{array}{l}\mathrm{NC}^{\alpha} \mathrm{C} \text { def }(25), \mathrm{NH} \text { opb (23), } \mathrm{C}=\mathrm{O} \\
\mathrm{ipb}(17)\end{array}$ \\
\hline & 285 & & 290 & & & $\begin{array}{l}\mathrm{C}^{\alpha} \mathrm{CN} \text { def }(58), \mathrm{NC}^{\alpha} \mathrm{C} \text { def }(18), \mathrm{NC}^{\alpha} \\
\text { str (12) }\end{array}$ \\
\hline & & 286 & & & & $\begin{array}{l}\mathrm{C}^{\alpha} \mathrm{CN} \text { def }(54), \mathrm{NC}^{\alpha} \mathrm{C} \operatorname{def}(21), \mathrm{NC}^{\alpha} \\
\operatorname{str}(12)\end{array}$ \\
\hline \multirow[t]{3}{*}{260} & & & & 257 & & $\begin{array}{l}\mathrm{CNC}^{\alpha} \text { def (38), } \mathrm{C}=\mathrm{O} \text { ipb (28), } \mathrm{NH} \\
\text { opb (12) }\end{array}$ \\
\hline & & & & & 257 & $\mathrm{CNC}^{\alpha} \operatorname{def}(38), \mathrm{C}=\mathrm{O} \mathrm{ipb}(27)$ \\
\hline & 217 & & 230 & & & $\mathrm{CNC}^{\alpha} \operatorname{def}(67), \mathrm{C}=\mathrm{O} \mathrm{ipb}(10)$ \\
\hline 211 & & 217 & & & & $\mathrm{CNC}^{\alpha}$ def $(75)$ \\
\hline \multirow[t]{4}{*}{$170(175)$} & & 181 & & & & $\mathrm{NH}$ opb (69), C= $=\mathrm{O}$ opb (14) \\
\hline & & & 179 & & & $\mathrm{NH}$ opb $(71), \mathrm{C}=\mathrm{O}$ opb $(18)$ \\
\hline & 140 & & & & 145 & $\mathrm{H} \cdots \mathrm{O} \operatorname{str}(52), \mathrm{CN}$ tor $(28), \mathrm{NH}$ opb (24) \\
\hline & & 134 & & & & $\mathrm{H} \cdots \mathrm{O} \operatorname{str}(30), \mathrm{CN}$ tor $(23), \mathrm{NC}^{\alpha} \mathrm{C} \operatorname{def}(12)$ \\
\hline \multirow[t]{2}{*}{$112(114)$} & & & & 110 & & $\mathrm{H}$. O str (79), CN tor (19) \\
\hline & & & 110 & & & $\mathrm{NC}^{\alpha} \mathrm{C}$ def (38), CN tor (15), $\mathrm{C}^{\alpha} \mathrm{C}$ tor (14) \\
\hline \multirow[t]{5}{*}{$82(87)$} & & 96 & & & & $\begin{array}{l}\mathrm{H}^{\alpha} \cdots \mathrm{H}^{\alpha} \operatorname{str}(31), \mathrm{NC}^{\alpha} \mathrm{C} \text { def }(22) \\
\mathrm{NH} \text { opb(15),H. O } \mathrm{str}(14)\end{array}$ \\
\hline & & & & 69 & & $\begin{array}{l}\mathrm{C}^{\alpha} \mathrm{C} \text { tor }(33), \mathrm{NC}^{\alpha} \text { tor }(32), \mathrm{NH} \cdots \mathrm{O} \\
\mathrm{ipb}(17)\end{array}$ \\
\hline & & & 34 & & & $\begin{array}{l}\mathrm{NH} \cdots \mathrm{O} \text { ipb (42), } \mathrm{C}=\mathrm{O} \cdots \mathrm{H} \text { ipb }(32), \\
\mathrm{H} \cdots \mathrm{O} \operatorname{str}(17)\end{array}$ \\
\hline & & & & 29 & & $\begin{array}{l}\mathrm{NH} \cdots \mathrm{O} \mathrm{ipb}(45), \mathrm{C}=\mathrm{O} \cdots \mathrm{H} \text { ipb }(35), \\
\mathrm{CN} \text { tor(11) }\end{array}$ \\
\hline & & 12 & & & & $\mathrm{NH}$ tor $(54), \mathrm{C}=\mathrm{O}$ tor $(37)$ \\
\hline
\end{tabular}

a Only contributions $10 \%$ or greater are included.

b Unperturbed frequency (cf. Table VIII).

c Frequencies at $120^{\circ} \mathrm{K}$ in parenthesis.

\section{NORMAL VIBRATION CALCULATIONS}

The foregoing spectroscopic arguments provide a sound basis for taking $(\text { Gly I })_{n}$ to be in an APRS structure. In our calculations we have assumed the rippled-sheet crystal structure proposed on the basis of electron diffraction analysis ${ }^{10}$ and conformational energy calculations. ${ }^{12}$ The exact values taken for the distance, $c$, between neighboring sheets and the magnitude of the angle, $\beta$, of the monoclinic unit cell will, of course, affect the values of the $F_{i j}^{\mathrm{I}}$ and $F_{i j}^{\mathrm{II}}$ interaction force constants determined by transition dipole coupling for the amide I and amide II modes, respectively.

The internal and local symmetry coordinates for the peptide group are given in Tables IIA and IIB, the notation being consistent with that used by Abe and Krimm. ${ }^{3}$ As mentioned previously, since the $\mathrm{C}=\mathrm{O} \cdots \mathrm{H}$ and 
$\mathrm{N}-\mathrm{H}$-.. O angles of APRS (Gly I) ${ }_{n}$ are nonlinear it is necessary to replace the in- and out-of-plane linear bending coordinates, $\Delta \gamma$, with angle bending, $\Delta \theta(\mathrm{C}=\mathrm{O} \cdots \mathrm{H})$ and $\Delta \theta(\mathrm{N}-\mathrm{H} \cdots \mathrm{O})$, and torsion, $\Delta \tau(\mathrm{C}=\mathrm{O})$ and $\Delta \tau(\mathrm{N}-\mathrm{H})$, coordinates.

The force field of Abe and $\mathrm{Krimm}^{3}$ was used as a starting point, 9 of the 72 intrachain force constants being rerefined to fit the observed frequencies of (Gly I $)_{n},(\mathrm{Ala})_{n}$, and (Ala-Gly) ${ }_{n}$. The $\mathrm{N}-\mathrm{H}$ stretching force constant was adjusted to make the calculated frequency agree with the unperturbed $\mathrm{N}-\mathrm{H}$ stretching frequency. Because of the close approach of the in-plane $\mathrm{H}^{\alpha}$ atoms, an $\mathrm{H}^{\alpha} \ldots \mathrm{H}^{\alpha}$ interaction force constant was introduced whose value is consistent with a Williams potential. ${ }^{33}$ Since such an interaction does not account for the observed splitting between ir and Raman active $\mathrm{CH}_{2}$ bending modes, it was necessary to adjust the two interaction constants $f\left(\mathrm{NC}^{\alpha} \mathrm{H}, \mathrm{HC}^{\alpha} \mathrm{H}\right)$ and $f\left(\mathrm{CC}^{\alpha} \mathrm{H}, \mathrm{HC}^{\alpha} \mathrm{H}\right)$ to get agreement with observation. The $f(\mathrm{C}=\mathrm{O}, \mathrm{O} \ldots \mathrm{H})$ interaction constant used previously ${ }^{3}$ was not found to be necessary, transition dipole coupling being capable of accounting for all of the amide I splittings. ${ }^{7}$ The final set of force constants is given in Table XI.

The calculated frequencies of (Gly I $)_{n}$, and our assignments to observed ir and Raman bands, are given in Table XII. Transition dipole coupling is incorporated for the amide I mode through $\mathrm{C}=\mathrm{O}$ stretch and for the amide II and amide III modes through $\mathrm{N}-\mathrm{H}$ bend. We have not attempted to include such coupling for other modes since they are less localized than amides I, II, and III, and therefore the intramolecular force field probably predominates in determining their frequencies. In addition, since their transition moments are nearer the chain axis (because of the mixing with skeletal modes), the magnitudes of interchain coupling effects are undoubtedly smaller than for the amide I, II, and III modes.

The agreement between observed and calculated frequencies is seen to be quite good. The splittings in the amide I and II modes are well reproduced, as noted earlier. The $\mathrm{CH}_{2}$ bending modes, which are calculated at $1441\left(A_{g}, A_{u}\right)$ and $1440\left(B_{u}, B_{g}\right) \mathrm{cm}^{-1}$ with $f\left(\mathrm{NC}^{\alpha} \mathrm{H}, \mathrm{HC}^{\alpha} \mathrm{H}\right)$ and $f\left(\mathrm{CC}^{\alpha} \mathrm{H}\right.$, $\mathrm{HC}^{\alpha} \mathrm{H}$ ) interaction constants of 0.05 , can be brought into agreement with the observed values of 1460 (Raman) and 1432 (ir) cm $\mathrm{cm}^{-1}$ by changing these force constants to 0.0767 and 0.0215 , respectively. The introduction of transition dipole coupling between amide III modes moves calculated bands at $1259\left(B_{u}\right)$ and $1259\left(B_{g}\right) \mathrm{cm}^{-1}$ up to 1284 and $1300 \mathrm{~cm}^{-1}$, respectively, thus permitting a satisfactory assignment of the weak $1295 \mathrm{~cm}^{-1}$ Raman band to an amide III mode. Weak bands at 1054 (ir) and 1034 (Raman) $\mathrm{cm}^{-1}$ are unassigned, although the $1034 \mathrm{~cm}^{-1}$ band may be due to a (Gly II $_{n}$ impurity. ${ }^{23}$ The other assignments are similar to those of Abe and Krimm, ${ }^{3}$ except for the $321 \mathrm{~cm}^{-1}$ ir band. In APRS (Gly I) ${ }_{n}$ this band is assigned to a $B_{u}$ mode with perpendicular dichroism, whereas in APPS (Gly $\mathrm{I}_{n}$ it was assigned ${ }^{3}$ to a mode with parallel dichroism, i.e., $B_{1}$ symmetry. In our present assignment this band is essentially an amide VII mode. 


\section{CONCLUSIONS}

In this paper we have presented the results of applying a refined force field to the calculation of the normal vibrations of APRS (Gly I) $)_{n}$. This force field incorporates transition dipole coupling 6,7 in accounting for splittings in amide I, II, and III modes, as well as taking hydrogen bond interactions explicitly into account. It is thereby possible not only to explain splittings in the above modes as well as accounting for the low-frequency bands, but we have also been able to rationalize quantitatively the Fermi resonance origin of the amide A and B modes. Finally, this force field, as we shall show in succeeding papers, is completely transferable to other $\beta$ polypeptides, which are in the APPS structure, and with minor modifications to the $\alpha$-helix structure. It is therefore potentially capable of serving as a basis for the use of vibrational analysis in studying the conformational structure of peptides and proteins.

This research was supported by National Science Foundation Grants BMS74-21163 and MPS75-05239.

\section{References}

1. Jakeš, J. \& Krimm, S. (1971) Spectrochim. Acta 27A, 19-34.

2. Jakeš, J. \& Krimm, S. (1971) Spectrochim. Acta 27A, 35-63.

3. Abe, Y. \& Krimm, S. (1972) Biopolymers 11, 1817-1839.

4. Abe, Y.\& Krimm, S. (1972) Biopolymers 11, 1841-1853.

5. Moore, W. H. \& Krimm, S. (1974) United States-Japan Joint Seminar on "The Raman Spectroscopy of Biological Molecules," pp. 32-33.

6. Krimm, S. \& Abe, Y. (1972) Proc. Nat. Acad. Sci. U.S. 69, 2788-2792.

7. Moore, W. H. \& Krimm, S. (1975) Proc. Nat. Acad. Sci. U.S. 72, 4933-4935.

8. Pauling, L. \& Corey, R. B. (1951) Proc. Nat. Acad. Sci. U.S. 37, 729-740.

9. Pauling, L \& Corey, R. B. (1953) Proc. Nat. Acad. Sci. U.S. 39, 253-256.

10. Lotz, B. (1974) J. Mol. Biol. 87, 169-180.

11. Moore, W. H. \& Krimm, S. (1975) Biophys. J. 15, 189a.

12. Colonna-Cesari, F., Premilat, S. \& Lotz, B. (1974) J. Mol. Biol. 87, 181-191.

13. Miyazawa, T. (1960) J. Chem. Phys. 32, 1647-1652.

14. Miyazawa, T. \& Blout, E. R. (1961) J. Amer. Chem. Soc. 83, 712-719.

15. Chirgadze, Y. N. \& Nevskaya, N. A. (1973) Dokl. Akad. Nauk. SSSR 208, 447-450.

16. Sandeman, I. (1955) Proc. Roy. Soc., Ser. A 232, 105-113.

17. Suzuki, E. (1967) Spectrochim. Acta 23A, 2303-2308.

18. Bradbury, E. M. \& Elliott, A. (1963) Polymer 4, 47-59.

19. Moore, W. H. \& Krimm, S. (1976) Biopolymers, 15, 2465-2483.

20. Arnott, S., Dover, S. D. \& Elliott, A. (1967) J. Mol. Biol. 30, $201-208$.

21. Fraser, R. D. B., MacRae, T. P., Stewart, F. H. C. \& Suzuki, E. (1965) J. Mol. Biol. 11, $706-712$.

22. Chirgadze, Y. N., Shestopalov, B. V. \& Venyaminov, S. Y. (1973) Biopolymers 12, $1337-1351$.

23. Small, E. W., Fanconi, B. \& Peticolas, W. (1970) J. Chem. Phys. 52, 4369-4379.

24. Tsuboi, M. (1964) Biopolymer Symposia No. 1, 527-547.

25. Suzuki, S., Iwashita, Y., Shimanouchi, T. \& Tsuboi, M. (1966) Biopolymers 4, 337350 .

26. Miyazawa, T. (1960) J. Mol. Spectrosc. 4, 168-172.

27. Krimm, S. \& Kuroiwa, K. (1968) Biopolymers 6, 401-407. 
28. Krimm, S. \& Kuroiwa, K. (1967) Seventh International Congress of Biochemistry, Tokyo, Abstract J-183.

29. Itoh, K., Shimanouchi, T. \& Oya, M. (1969) Biopolymers 7, 649-658.

30. Fanconi, B. (1973) Biopolymers 12, 2759-2776.

31. Fukushima, K., Ideguchi, Y. \& Miyazawa, T. (1963) Bull. Chem. Soc. Jap. 36, 13011307.

32. Johnson, K. W., Krishnan, K. \& Rabolt, J. F. (1975) Bull. Amer. Phys. Soc. 20, 372. 33. Williams, D. E. (1967) J. Chem. Phys. 47, 4680-4684.

Received May 10, 1976

Accepted July 12, 1976 